\title{
The formation and influence mechanism of mathematics self-concept of left-behind children in mainland China
}

\author{
Zhichen Xia $^{1} \cdot$ Fan Yang $^{1} \cdot$ Kevin Praschan ${ }^{1} \cdot$ Qingyu Xu ${ }^{1}$ (D) \\ Published online: 9 November 2019 \\ (C) The Author(s) 2019
}

\begin{abstract}
This study aimed at exploring the formation mechanism of mathematics self-concept of left-behind children and the influence mechanism of mathematics self-concept on their mathematics achievement. In study 1, the formation mechanism of mathematics self-concept was examined using multilevel analyses of 874 left-behind children. The results showed that (1) the individual mathematics achievement of left-behind children had a significant positive predictive effect on mathematics self-concept, Chinese achievement had a significant negative predictive effect on mathematics self-concept, and the class-average mathematics achievement had no significant effect on mathematics self-concept; and (2) when left-behind children were the majority group, there was an assimilation effect on downward interpersonal social comparison. When left-behind children were the minority group, there was a contrast effect on upward intergroup social comparison. In study 2, the influence mechanism of mathematics self-concept of 585 left-behind children was investigated with a tracking research. The results suggested that (1) Time 1 mathematics self-concept had significant effects on Time 2 mathematics school engagement at between-group and withingroup levels; and (2) Time 2 mathematics school engagement played a partial mediating role between Time 1 mathematics self-concept and Time 2 mathematics achievement at the within-group level. These results indicate that the formation and influence mechanism of mathematics self-concept of left-behind children is influenced by contextualized characteristics.
\end{abstract}

Keywords Mathematics self-concept · Left-behind children · Internal/external frame of reference model · Big-fish-little-pond effect $\cdot$ Interpersonal and intergroup comparison $\cdot$ School engagement

\section{Introduction}

Academic self-concept expresses how students perceive their own skills as a result of the feedback and experience gained in a school environment (Cetinkaya 2017). Academic selfconcept was first proposed by Shavelson et al. (1976) in their theory of hierarchical and multidimensional self-concept. Since then, it has been used in almost all academic domains, including mathematics, English, science, and some other subjects, for which it is divided into somewhat different selfconcepts corresponding to different domains. Marsh and Shavelson (1985) posited a revised Marsh/Shavelson model that focused on the two core domains of mathematics and verbal academic self-concepts. The substantial relationship between academic self-concept and desirable outcomes, such

\section{Qingyu Xu}

qyxu@suda.edu.cn

1 School of Education, Soochow University, No.1 Wenjing Road, Industrial Park District, Suzhou, China as achievement performance, academic success, has been demonstrated (Mendaglio 2013; Parker et al. 2014; Trautwein and Moller 2016). For example, Pinxten et al. (2014) reported that mathematics self-concept had positive effects on mathematics achievement in Belgian primary school students, and Chen et al. (2015) noted that academic self-concept is conducive to the academic achievement of Taiwanese students. Thus, understanding the formation and influence mechanism of academic self-concept is a major concern in educational settings.

Research has proven that comparisons are important antecedents of academic self-concept (Marsh and Martin 2011; Möller and Marsh 2013). The studies of academic selfconcept formation mainly focused on the dimension comparison and social comparison effects that emanated from the internal/external frame of reference model (I/E model) and the big-fish-little-pond effect (BFLPE) (Chmielewski et al. 2013; Pinxten et al. 2015). In addition, Byrne (1996) found that gender, cognitive ability, socioeconomic status, and other demographic variables could influence the formation of academic self-concept. Although academic self-concept 
formation and the factors related to it have been extensively investigated, little is known about the formation of academic self-concept in left-behind children. We cannot ascertain the extent to which we can transfer our general knowledge about academic self-concept development on left-behind children.

Left-behind children are a universal phenomenon, but the regions with the greatest number of left-behind children include China, Philippines, and Moldova (Tarroja and Fernando 2013; Vanore et al. 2015). These developing countries have been undergoing rapid industrialization and urbanization, and large-scale rural-urban migrations or international labor migration lead to an increased number of left-behind children. The left-behind children are characterized by the separation from parents, remaining in their rural hometowns and left in the care of relatives or others. Left-behind children are more vulnerable to problems, such as psychological pressure (He et al. 2012; Hu et al. 2014), emotional problems (Fan et al. 2010; Gao et al. 2010), low self-esteem (Luo et al. 2012; Sun et al. 2015), loneliness (Jia and Tian 2010; Ai and $\mathrm{Hu} 2016$ ), anxiety (Zhao et al. 2014), and behavioral problems (Fan et al. 2010). A meta-analysis focusing on left-behind children in China suggested that the negative impact of parental migration is consistent with research on left-behind children from other countries (e.g., Philippines, Sri Lanka, Ecuador, Mexico) (Valtolina and Colombo 2012).

Owing to long-term parent-child separation, parental migration has a negative impact on children's academic achievements (Wang and Mesman 2015; Zhao and Yu 2016). Academic problems of left-behind children have become a research focus over the past decade (Roy et al. 2015; Li et al. 2017; Bai et al. 2018). McKenzie and Rapoport (2011) found that family migration reduces the educational attainments of the rural Mexican children. Zhang et al. (2014) found that the absence of both migrant parents significantly reduced the learning achievements of Chinese left-behind children. Cortes (2015) found that Filipino children with migrant mothers were more likely to lag behind in their learning compared to children of non-migrant parents. In short, left-behind children are more likely to get low scores in academic examinations than non-left-behind children (Fu et al. 2017). Additionally, Yao and Mao (2008) and Wang et al. (2014) found that the academic self-concept of left-behind children was lower than that of peer non-left-behind children.

Despite these common characteristics and problems, however, due to the unique social structure and household registration system (hukou), left-behind children in China are different from those in other places (Liu et al. 2017). First, according to the data in 2017, there are more than 68 million leftbehind children in China, which is an important segment of the population that needs to be taken seriously (Duan et al. 2017). Second, the current public opinion toward left-behind children in China is negative, and their academic, psychological, and behavioral problems have been gradually exaggerated, labeled, and stigmatized (Gu et al. 2011). These children have been labeled as inferior, which contributes to their psychological sense of inferiority. Third, the Chinese Government has issued plans and implemented programs to address the education of rural left-behind children in the stage of compulsory education (State Council of the People's Republic of China 2016). Attention to the academic self-concept of left-behind children should be helpful in reducing the urban-rural educational inequality and ultimately driving societal development in China as a whole (Wen and Lin 2012).

Despite the voluminous extant literature on the subject, few studies have examined the academic self-concept of leftbehind children, resulting in significant gaps in our understanding of their academic self-concept. First, previous research may neglect potential subgroups in the social context, especially when members of the groups endowed with specific values make in-group comparison or out-group comparison in the social comparison process; these special experiences may influence the formation of academic self-concept. Second, few studies have established how academic selfconcept improves academic achievement in the elementary school context. Considering that academic self-concept plays an eminent role in students' educational outcomes, it is important to understand how the academic self-concept is formed and to identify the mechanism that facilitates academic achievement in left-behind children. The present study is aimed at filling these research gaps. Accordingly, our research aims to (1) examine whether the formation of mathematics self-concept of left-behind children is consistent with previous findings; (2) conduct an exploratory analysis on the effects of in-group comparison or out-group comparison in the formation of mathematics self-concept process; and (3) test the influence mechanism of mathematics self-concept on leftbehind children's mathematics achievement through a longitudinal design.

The study focuses on the academic domain of mathematics for two reasons. First, Chinese teachers traditionally espouse the belief that "You will have no trouble across the world once you've learned mathematics, physics, and chemistry well." Chinese teachers generally believe that mathematics is the most basic and important subject that primary and secondary school students should learn, and that every child has the ability to learn mathematics well regardless of their family background. Expectedly, in the Program for International Student Assessment (PISA) 2012, Chinese students performed well in mathematics tests (Organization for Economic Cooperation and Development, 2014). The second reason is that mathematics is a critical academic filter for students' educational pathways (Chiu and Klassen 2010). Moreover, it is one of the core competencies in the twenty-first century, which enable individuals to meet the requirements for participating in schools, society, and the labor market (European Commission 2011). 


\section{Literature Review and Hypotheses}

\section{Mechanisms for the Formation of Mathematics Self-Concept}

The main theories of academic self-concept formation include the internal/external frame of reference model (I/E Model; Marsh 1986) and the big-fish-little-pond effect (BFLPE; Marsh 1987). The I/E model states that the formation of academic self-concept in a specific domain is the combined result of dimension comparison and social comparison (Marsh 1986). Dimension comparison, or internal comparison, refers to the comparison between students' academic achievements in one domain and their achievements in other domains. For example, if a student's mathematics achievement is higher than his/her English achievement, then he/she will acquire a higher mathematics self-concept and a lower English self-concept. Social comparison, or external comparison, refers to the comparison of a student's achievements in one domain with those of other students in the same domain. For example, if the mathematics achievement of a student is higher than the mathematics achievement of the other students in the class, he/she will acquire a higher mathematics self-concept. According to the $\mathrm{I} / \mathrm{E}$ model, self-concept in a particular domain is not only positively affected by one's ability in matching domains but also negatively affected by one's ability in non-matching domains (Möller et al. 2009). Some scholars have taken children of different ages, genders, and countries as subjects and used different versions of self-concept questionnaires as tools to conduct research. The results obtained in these studies have supported the theoretical assumptions of the I/E model (Marsh and Hau 2004; Möller et al. 2009; Marsh et al. 2015).

The most representative theory on the role of social comparison in the formation of academic self-concept is the BFLPE. It focuses on the cross-level situational effect of social comparison; this implies that students with the same ability gain a lower academic self-concept when they enter a highlevel situation than when they enter a low-level situation. In fact, the BFLPE is the result of social comparison. Currently, the class- or school-average academic achievement is taken as the external reference standard. The contrast effect indicates that the class- or school-average academic achievement has a negative influence on the formation of individual academic self-concept. For individuals, the average academic achievement level of the class or the school cannot be chosen, and social comparison here is the forced upward comparison caused by the educational environment. It has been confirmed that this effect is universal across cultures (Wang 2015) and domains (Liou 2014).

The I/E model highlights the dimension comparison between different domains and the social comparison at the individual level of a particular domain. The BFLPE emphasizes the social comparison at the group level of a specific domain. Two typical studies that combined the $\mathrm{I} / \mathrm{E}$ model and the BFLPE successfully are by Chiu (2012) and Parker et al. (2013). The results obtained in these studies proved that the integrated model could simultaneously realize the dimension comparison of different domains at the individual level and the social comparison of specific domains at the group level. In order to explore whether dimension and social comparisons play a role in the formation of mathematics selfconcept of left-behind children, the applicability of the integrated model is examined in this study. Moreover, considering that mathematics and verbal are the two core domains of academic self-concept (Marsh 1990a, 1990b) and that mathematics and Chinese are the main subjects in many primary schools in mainland China, Chinese is chosen as the nonmatching domain relative to mathematics in this study. The combined model will be as follows: left-behind children's mathematics self-concept (the dependent variable for both the I/E Model and the BFLPE) is predicted by their mathematics achievement (a major predictor for the I/E Model), Chinese achievement (a major predictor for the I/E Model), and Chinese self-concept (a controlling variable for the $\mathrm{I} / \mathrm{E}$ Model) and class-average mathematics achievement (a major predictor for the BFLPE). Thus, the following hypothesis is put forward:

Hypothesis 1 Left-behind children's mathematics self-concept is positively predicted by individual mathematics achievement; however, it is negatively predicted by individual Chinese achievement and class-average mathematics achievement, controlling for left-behind children's Chinese selfconcept.

Typically, the effects size of social comparisons are large, whereas the effects of dimensional comparisons are relatively small (Möller et al. 2009). Social comparison in the I/E model and the BFLPE displays that academic self-concept is not only influenced by the individual ability of students but also depends on the class environment. Being surrounded by high achieving students allows for more opportunities for upward comparisons, which relates to a lower academic self-concept; in contrast, belonging to a low achieving group of students, the opportunities for downward comparisons increase, resulting in a more positive academic self-concept (Köller et al. 2006). The study by Schurtz et al. (2014) found that students with above-average grades reported higher mathematics self-concepts compared with the average performance of their peers (downward comparison), whereas students with below-average grades reported lower mathematics selfconcepts compared to students with class-average grades (upward comparison). Thus, the most salient reference group is usually students' class environment (Wouters et al. 2013) and the academic self-concept is impacted by the composition of the class (Dumont et al. 2017; Stäbler et al. 2017). However, little is known about the specific relations of classroom 
compositions including left-behind children and the formation of academic self-concept.

Furthermore, the influence of belonging to a certain social group (e.g., race, ethnicity, gender, or social class) on students' self-evaluations of abilities is salient (Walton and Cohen 2007; Fryberg and Townsend 2008; Herrmann et al. 2015). For example, compared to majority students, minority students are more likely to shape negative stereotypes about their ability and intelligence (Cvencek et al. 2015), due to a lack of positive academic models (Covarrubias and Fryberg 2015). When there are different groups in a class, group members may refer to the class-average academic achievement and the in-group or out-group average academic achievement as the reference standard. Interpersonal social comparison occurs when the in-group members provide the reference standard for social comparison. Intergroup social comparison occurs when the average academic achievement of the out-group members is taken as the reference standard for comparisons between one's in- and out-group. Whether or not individuals make interpersonal social comparisons or intergroup social comparisons, will be influenced by the size of the group they belong to. According to Brewer's (1991) optimal distinctiveness theory, humans have a need for similarity with others and a countervailing need for uniqueness. This contradiction urges the individual to find a balance between the two. In order to meet their needs for distinctiveness, the majority-group members tend to engage in interpersonal social comparison. Meanwhile, the minority-group members meet their needs for uniqueness through intergroup social comparison (Brewer and Weber 1994).

In the frame of social comparison, contrast effects as well as assimilation effects have been deemed as counterbalancing mechanisms in academic self-concept research (Marsh et al. 2000; Chmielewski et al. 2013). Contrast effects rely on students comparing their achievement with that of their peers, which are negative comparison results (Huguet et al. 2009). Assimilation effects typically result from belonging to a higher achieving group or a group with a positive value attached, which are usually positive self-evaluation (Cialdini et al. 1976). At the same time, negative assimilation or stigmatization effects also exist, which derives from belonging to a group with a negative value attached (Knigge and Hannover 2011; Dumont et al. 2017). The present study predicted that the outcome of social comparison would differ depending on whether the interpersonal or intergroup comparison process has been engaged. What role does upward comparison and downward comparison play in the formation of mathematics self-concept in classes with different proportions of leftbehind children? How do contrast effects and assimilation effects manifest in the process of formation of mathematics self-concept? Although Western social psychology studies provide a reference to an answer for the above questions, in the context of Chinese culture, collectivism emphasizes interdependence rather than difference (Triandis 1989). Based on the above discussion, the existences of contrast effect on upward comparison and assimilation effect on downward comparison in the process of mathematics self-concept were explored in this unifying model, and the following hypotheses are proposed:

Hypothesis 2 When left-behind children are the majority group in a class, the average mathematics achievement of the left-behind children has a contrast effect on the mathematics self-concept of left-behind children through interpersonal upward comparison (see model 3 in Table 3) or an assimilation effect on interpersonal downward comparison (see model 7 in Table 4).

Hypothesis 3 When left-behind children are the minority group in a class, the average mathematics achievement of the non-left-behind children has a contrast effect on the mathematics self-concept of left-behind children through intergroup upward comparison (see model 6 in Table 3) or an assimilation effect on intergroup downward comparison (see model 10 in Table 4).

\section{Mechanisms for Explaining the Influence of Mathematics Self-Concept}

The relationship between academic self-concept and academic achievement has been thoroughly discussed in the literature. Various studies on academic self-concept have consistently highlighted its strong relationship with academic achievement (Marsh and Martin 2011; Retelsdorf et al. 2014). The self-enhancement model posits that prior academic self-concept can lead to changes in subsequent academic achievement (Calsyn and Kenny 1977; Valentine et al. 2004). The skill-development model considers that prior academic achievement has a great influence on the formation of subsequent academic selfconcept (Calsyn and Kenny 1977; Skaalvik and Hagtvet 1990). The reciprocal effects model (REM) defines the relationship between academic self-concept and academic achievement as mutual enhancement and mutual causation (Marsh and Martin 2011). Research methods, instruments, participants, cultures, and environment may cause the differences in the outcomes of the three models (Chen et al. 2015). It is worth mentioning that none of these models is superior to the others (Skaalvik and Skaalvik 2009). This study is based on the self-enhancement model and takes left-behind children in China as subjects to investigate the main effects of mathematics self-concept as an independent variable. Studies by Chinese scholars on elementary school students as subjects have supported the selfenhancement model (Yang 2008; Chen and Shi 2016). Therefore, the following hypothesis is proposed: 
Hypothesis 4 The mathematics self-concept of left-behind children at Time 1 has a positive predictive effect on the mathematics achievement of left-behind children at Time 2 .

Academic self-concept belongs to a kind of cognitive evaluation. How does this kind of cognitive evaluation affect academic achievement, and what is the mechanism? In the motivation model of "context-self-action-outcome" proposed by Connell and Wellborn (1991), there is a causal relationship among background characteristics, self-concept, behavior pattern, and adjustment result. Specific to the academic field, school engagement is the most responsive behavior to social contexts, and left-behind children have the disadvantage in terms of school engagement (Wen and Lin 2012). Considering that school engagement may be the most amenable to social interventions (Wen and Lin 2012), school engagement can further positively influence academic achievement (Susperreguy et al. 2017). In the present study, school engagement can be considered the behavior pattern and academic achievement can be considered the adjustment result. Therefore, school engagement is considered an antidote for alleviating poor academic achievement (Fredricks et al. 2004).

School engagement is a multidimensional construct. Behavioral engagement, emotional engagement, and cognitive engagement are widely accepted as the three dimensions of school engagement (Finn 1989; Fredricks et al. 2004; Glanville and Wildhagen 2007). Behavioral engagement refers to participation in classroom and school activities. Emotional engagement refers to positive or negative emotional reactions to the school. Cognitive engagement mainly describes the extent to which students are willing to make longterm efforts to think deeply when dealing with complex learning content and mastering difficult skills. These three dimensions of school engagement are closely related to academic achievement. Previous studies have found that there is a positive correlation between behavioral engagement and results related to the performance (standard tests and academic grades) of students (Connell et al. 1994; Marks 2000). Moreover, behavioral engagement has a lasting impact on academic achievement (Alexander et al. 1993). In a study involving white students belonging to Grades 4-7, Voelkl (1997) confirmed that emotional engagement was significantly correlated with test scores. By employing metacognitive strategies, such as managing their attention and effort, building connections between new and old knowledge, and taking the initiative to test their understanding, students can improve their academic performance (Boekarts et al. 2000).

Further, in the motivation model by Connell and Wellborn (1991), school engagement is closely associated with academic self-concept and academic achievement. In addition, academic self-concept has a significant influence on school engagement (Connell et al. 1994). Studies reveal that academic self-concept can significantly affect school engagement and academic achievement (Buhs 2005). Moreover, school engagement may mediate the relationship between academic self-concept and academic achievement. On the basis of these findings, the following hypothesis is put forward:

Hypothesis 5 Mathematics school engagement at Time 2 plays a mediating role in the relation between mathematics selfconcept at Time 1 and mathematics achievement at Time 2.

\section{The Present Study}

Although the formation and influence mechanism of academic self-concept have been investigated in various populations, little is known about its characteristics in left-behind children. We deem it imperative to provide rigorous empirical evidence on the development of academic self-concept in left-behind children. To test the above research hypotheses, a tracking research was carried out in this research. In the first study, we investigated the formation mechanism of mathematics self-concept of left-behind children. On the one hand, we verified whether it matches the combined I/E-BFLPE model. On the other hand, from the perspective of interpersonal and intergroup social comparisons, we examined comparison effects when left-behind children are the majority or the minority group in a class. In the second study, we used mathematics self-concept as an independent variable and explored the impact of mathematics self-concept on mathematics achievement through mathematics school engagement. We used a longitudinal design with two measurement points-Time 1 (T1): the start of the autumn academic year of 2017 and Time 2 (T2): the start of the spring academic year of 2018.

\section{Materials and Methods-Study 1}

\section{Participants and Procedure}

Random cluster sampling was carried out and we randomly selected nine schools from the Anhui province of mainland China, as it is a large labor-export province in the east of mainland China. All students' data were collected in the classroom at T1. Questionnaires given to the students were completed in less than 20 min. After selecting the schools, we randomly selected 6 classrooms, calculating about 220 subjects per school. A total of 2000 students participated in Study 1 , from Grades 4 to 6 . After removing classes with fewer than 5 students to assure a reliable estimate of class-average achievement, the final sample consisted of 1936 students from 52 classes ( 909 boys and 1006 girls; 874 left-behind children and 1062 non-left-behind children; average age, 11.57 years $[\mathrm{SD}=1.103])$. The proportion of left-behind children in each class ranged from $15.8 \%$ to $90.0 \%$. The study was approved by the Academic Ethical Group of the Faculty of Education, 
Soochow University of China, and the students and their parents or legal representatives were informed of all the process and purpose of the research by the related schools. Thus, a written informed parental consent was obtained for all students participating in the study.

\section{Materials}

\section{Academic Self-Concept}

Academic self-concept was measured using the SelfDescription Questionnaire-II (SDQ-II) (Marsh et al. 1984). The questionnaire contained 20 items and 2 subscales: mathematics self-concept (10 items) and verbal self-concept (10 items). We changed verbal-related content to Chinese-related content. All 20 items were rated on a 6-point scale, ranging from 1 (completely false) to 6 (completely true). High scores indicate a high self-concept, whereas low scores indicate a low self-concept. Chen and Cui (1997) performed the Chinese adaption of SDQ-II, and they found that the Chinese version of SDQ-II had estimates of internal consistency and test-retest reliability within an acceptable range. Cronbach's alpha coefficients in this study were 0.841 (mathematics self-concept) and 0.864 (Chinese self-concept).

\section{Achievement Grade}

Students' mathematics and Chinese grades were obtained from their self-reports. School grades ranged from 1 to 5, with 1 representing the poorest and 5 the best grade. The mean was calculated, with higher values indicating higher levels of achievement.

\section{Average Mathematics Grade}

The class-average mathematics grade was the average of the mathematics grades of all students within a class. "Left-behind children-average mathematics grade" was the average of the mathematics grades of the left-behind children within a class. "Non-left-behind children-average mathematics grade" was the average of the mathematics grades of the non-left-behind children in a class.

\section{Control Variables}

Control variables included gender, age, and parents' socioeconomic status (measured through parents' educational level, parents' occupation, and family income; Bradley and Corwyn 2002). The control variables were selected based on empirical research on disparities in academic self-concept and achievement. We controlled for gender since past research has conveyed that gender influences both mathematics selfconcept and mathematics performance (Hyde et al. 1990).
Further, we controlled for age because a great deal of studies found age-related differences in self-concept and achievement (Eccles et al. 1993; Ehm et al. 2014). Furthermore, we controlled for parents' socioeconomic status because it was statistically significant for predicting students' mathematics achievement (Karakolidis et al. 2016) and mathematics selfconcept (Rinn et al. 2013).

\section{Statistical Analyses}

We analyzed the formation mechanism of left-behind children's academic self-concept in mathematics by using two analytical steps. First, we analyzed whether left-behind children's mathematics self-concept fit the combined I/E-BFLPE model. In the second step, we estimated the influence of interpersonal and intergroup social comparisons, that is, the effect of average mathematics grades of left-behind and nonleft-behind children on the formation of left-behind children's mathematics self-concept.

To distinguish left-behind children from the majority or minority group in the class, we defined left-behind children as the majority group when their proportion in the class was more than 50\%. Moreover, in the process of upward social comparison, children whose mathematics grade was higher than the average grade of left-behind children or non-leftbehind children were excluded; in the process of downward social comparison, individuals whose mathematics grade was lower than the average grade of left-behind children or nonleft-behind children were excluded.

Multilevel analysis allows researchers to test complex multilevel models, by including both individual- and class-level variables together; this addresses the issues of both dimension and social comparisons. We chose multilevel analysis as the major statistical method to examine the posited hypotheses. We conducted multilevel linear modeling in HLM6.02 in two steps. Hierarchical linear modeling allowed us to take into account the non-independence of individuals nested within classes by simultaneously modeling within-class and between-class variance (Raudenbush and Bryk 2002). We grand-mean centered all continuous variables at the individual level, so that the incremental effects from classes could be identified (Raudenbush and Bryk 2002). The interaction effect was not considered in the present study, so the analysis was limited to random intercept models.

To illustrate the procedure used in the present study, we used left-behind children's mathematics self-concept as the dependent variable, building a two-level model (empty model) without adding any variables. The model can be represented as follows:

- Level $1 \mathrm{MASC}_{i j}=\beta_{0 j}+e_{i j}, e_{i j} \sim N\left(0, \sigma^{2}\right)$

- Level $2 \beta_{0 j}=y_{00}+u_{0 j}, u_{0 j} \sim N\left(0, \tau_{00}\right)$ 
$\mathrm{MASC}_{i j}$ is the mathematics self-concept of left-behind children $i$ in class $j, \beta_{0 j}$ is the average mathematics self-concept in each class, and $e_{i j}$ is the Level 1 error term. $e_{i j}$ is assumed to be normally distributed, with a mean equal to zero and a constant Level 1 variance. $y_{00}$ is the average mathematics self-concept in all classes, and $u_{0 j}$ is the Level 2 error term. $u_{0 j}$ is assumed to be normally distributed, with a mean equal to zero and a constant Level 2 variance.

Second, we considered a model with one individual-level variable and one class-level variable. In the Level 1 model, mathematics self-concept of left-behind children was predicted using their mathematics grade, with intercept $\beta_{0 j}$, slope $\beta_{1 j}$, and residual term $e_{i j}$. There were two Level 2 models. The intercept model for $\beta_{0 j}$ included class-average mathematics grade as the variance and was allowed to vary across classes, by setting its residual term $u_{0 j}$ to be estimated. The slope model for $\beta_{l j}$ did not include any variance and was not allowed to vary across classes.

This model can be represented as follows:

- Level $1 \mathrm{MASC}_{i j}=\beta_{0 j}+\beta_{l j} \mathrm{MAG}_{i j}+e_{i j}, e_{i j} \sim N\left(0, \sigma^{2}\right)$

- Level $2 \beta_{0 j}=y_{00}+y_{01} \mathrm{CAG}_{i j}+u_{0 j}, u_{0 j} \sim N\left(0, \tau_{00}\right) \beta_{1 j}=y_{10}$

Multilevel analysis allows for a number of Level 1 and Level 2 variables to be freely included in the models and produces estimates for a regression coefficient and a standard error, which will be used to determine the significance of the coefficient. In all models, we controlled for gender, age, and parents' socioeconomic status. Gender was a virtual variable: female $=0$, male $=1$.

\section{Results}

\section{Preliminary Analysis}

Descriptive statistics and correlations for individual- and class-level variables are presented in Table 1. Correlation analysis showed that left-behind children's mathematics selfconcept was significantly positively related to mathematics grade $(r=0.461, p<0.01)$ and Chinese self-concept $(r=$ $0.738, p<0.01$ ) but was significantly negatively related to Chinese grade $(r=-0.234, p<0.01)$.

Significant differences were observed between left-behind children's mathematics self-concept $(M=4.392, S D=0.686)$ and non-left-behind children's mathematics self-concept $(M=$ 4.522, $S D=0.725)[t(1897)=-4.040, p<0.05]$; moreover, left-behind children's mathematics self-concept was significantly lower than that of non-left-behind children.

\section{Hierarchical Linear Model Analyses}

We conducted a nested hierarchical analysis by using HLM6.02 (Raudenbush et al. 2008) to determine the effects of individual- and class-level variables on individual-level mathematics self-concept. Model 1 was an empty model. Using the residual variance values, we could determine the intra-class correlation (ICC). ICC $(1)=0.095 /(0.095+$ $0.389)=0.1964$, indicating that $19.64 \%$ of the mathematics self-concept variance resides between classes $\left[\left(\chi^{2}(51)=\right.\right.$ $238.104, p<0.01)]$. Because there was significant variance between classes, HLM analysis was appropriate for these data.
Table 1 Descriptive statistics and correlations

\begin{tabular}{|c|c|c|c|c|c|c|c|c|}
\hline $\begin{array}{l}\text { Individual-level } \\
\text { variables }\end{array}$ & Mean & SD & 1 & 2 & 3 & 4 & 5 & 6 \\
\hline $\begin{array}{l}\text { 1. Mathematics } \\
\text { Self-concept }\end{array}$ & 4.463 & 0.711 & & & & & & \\
\hline $\begin{array}{l}\text { 2. Mathematics } \\
\text { Grade }\end{array}$ & 3.540 & 0.957 & $0.461^{* *}$ & & & & & \\
\hline 3. Chinese Grade & 3.150 & 1.162 & $-0.234^{* *}$ & $-0.184^{* * *}$ & & & & \\
\hline $\begin{array}{l}\text { 4. Chinese } \\
\text { Self-concept }\end{array}$ & 4.497 & 0.833 & $0.738^{* *}$ & $0.284^{* *}$ & $-0.168^{* *}$ & & & \\
\hline 5. Gender & 0.470 & 0.499 & $0.085^{* *}$ & 0.028 & -0.019 & $-0.095^{* *}$ & & \\
\hline 6. Age & 11.579 & 1.103 & $-0.090^{* *}$ & $-0.060^{* *}$ & $0.185^{* *}$ & $-0.060^{* *}$ & 0.038 & \\
\hline $\begin{array}{l}\text { 7. Parents' } \\
\text { Socioeconom- } \\
\text { ic Status }\end{array}$ & 18.278 & 6.372 & $0.195^{* *}$ & $0.133^{* *}$ & $-0.074^{* *}$ & $0.163^{* *}$ & $0.070^{* *}$ & $-0.145^{* *}$ \\
\hline $\begin{array}{c}\text { Class-Level } \\
\text { variables }\end{array}$ & Mean & SD & 1 & & & 2 & & \\
\hline 1. LBCA-MG & 3.432 & 0.334 & & & & & & \\
\hline 2. NLBCA-MG & 3.572 & 0.279 & $0.525^{* * *}$ & & & & & \\
\hline 3.CA-MG & 3.509 & 0.266 & $0.860^{* * *}$ & & & $0.795^{* * *}$ & & \\
\hline
\end{tabular}

$L B C A-M G$ Left-behind children-average mathematics grade, $N L B C A-M G$ Non-left-behind children-average mathematics grade, $C A-M G$ Class-average mathematics grade ${ }^{*} p<0.05 ;{ }^{* *} p<0.01 ;{ }^{* * *} p<0.001$ 
The results illustrate (see Table 2) the following: (1) leftbehind children's mathematics self-concept was positively predicted by individual mathematics grade $(\beta=0.284$, $p<0.001)$ and negatively predicted by Chinese grade $(\beta=$ $-0.074, p<0.01)$; (2) the effect of class-average mathematics grade was not significant statistically $(\beta=-0.011, p>0.05)$, which was inconsistent with the conclusions of previous studies.

The high correlation between Chinese self-concept and mathematics self-concept revealed by correlation analysis exists a potential problem of collinearity. The results pertaining to the combined model are qualitatively the same whether they include Chinese self-concept or not but are clearer if it is omitted. So Chinese self-concept is excluded for purposes of clarity from the analyses (but see the Appendix 1 for the presentation of all parameter estimates). The same considerations apply to the analyses about upward social comparisons (Table 3) and downward social comparisons (Table 4).

For left-behind children as the majority group, ICC (2)= $0.087 /(0.087+0.384)=0.1847$, indicating that $18.47 \%$ of the mathematics self-concept variance resides between classes $\left[\left(\chi^{2}(22)=136.983, p<0.01\right)\right]$. For left-behind children as the minority group, ICC $(3)=0.106 /(0.106+0.399)=$ 0.2099 , indicating that $20.99 \%$ of the mathematics selfconcept variance resides between classes $\left[\left(\chi^{2}(26)=85.201\right.\right.$, $p<0.01)]$. HLM analysis was appropriate for these data as there were significant variances between classes. Table 3

Table 2 Tests of combined model

\begin{tabular}{|c|c|c|c|}
\hline \multirow[t]{2}{*}{ Variable } & Model 1 & \multicolumn{2}{|l|}{ Model 2} \\
\hline & $\mathrm{SE}$ & $\beta$ & SE \\
\hline \multicolumn{4}{|l|}{ Fixed Effect } \\
\hline \multicolumn{4}{|l|}{ Level 1: Individual variables } \\
\hline Gender & & $0.116^{* *}$ & 0.040 \\
\hline Age & & $-0.065^{* *}$ & 0.019 \\
\hline Parents' Socioeconomic Status & & 0.004 & 0.003 \\
\hline Mathematics Grade & & $0.284^{* * *}$ & 0.024 \\
\hline Chinese Grade & & $-0.074^{* *}$ & 0.024 \\
\hline \multicolumn{4}{|l|}{ Level 2: Class-level variables } \\
\hline CA-MG & & -0.011 & 0.116 \\
\hline \multicolumn{4}{|l|}{ Random Effect } \\
\hline $\operatorname{Intercepts}\left(\tau_{00}\right)$ & $0.095^{* * * *}$ & $0.068^{* * * *}$ & \\
\hline $\operatorname{Residual}\left(\sigma^{2}\right)$ & 0.389 & 0.297 & \\
\hline \multicolumn{4}{|l|}{ Model summary } \\
\hline Deviance(-2LL) & 1732.489 & 1518.819 & \\
\hline
\end{tabular}

$\beta$ is the unstandardized regression coefficient

Control variables are gender, age, and parents' socioeconomic status at Level 1

$C A-M G$ Class-average mathematics grade

${ }^{*} p<0.05 ;{ }^{* *} p<0.01 ;{ }^{* * *} p<0.001$ shows the interpersonal and intergroup upward social comparison for different groups. When the left-behind children were the majority group, the average mathematics grade of the leftbehind children had no significant influence on their mathematics self-concept through interpersonal upward social comparison $(\beta=-0.123, p>0.05$; Model 3$)$ or through intergroup upward social comparison $(\beta=0.117, p>0.05$; Model 4$)$. When the left-behind children were the minority group, the average mathematics grade of the non-left-behind children had a significantly negative effect on the left-behind children's mathematics self-concept through intergroup upward social comparison $(\beta=-3.240, p<0.05$; Model 6$)$ but had no significant influence through interpersonal upward social comparison ( $\beta=0.601, p>0.05$; Model 5).

Table 4 presents the interpersonal and intergroup downward social comparison for different groups. When the leftbehind children were the majority group, their average mathematics grade had a significantly positive effect on their mathematics self-concept through interpersonal downward social comparison ( $\beta=1.449, p<0.05$; Model 7$)$ but had no significant influence through intergroup downward social comparison $(\beta=-0.118, p>0.05$; Model 8$)$. When the left-behind children were the minority group, the average mathematics grade of the non-left-behind children had no significant effect on left-behind children's mathematics self-concept through intergroup downward social comparison $(\beta=0.3778$, $p>0.05$; Model 10) or through interpersonal downward social comparison $(\beta=0.17, p>0.05$; Model 9).

\section{Discussion}

Many scholars have verified the validity of the I/E model and the BFLPE in explaining the formation of academic selfconcept (Möller et al. 2014; Parker et al. 2014). This study took left-behind children as research subjects, and results revealed that the combined model was supported partially. That mathematics self-concept was related to mathematics achievement and Chinese achievement was not surprising given that extant research indicated a strong relationship between selfconcept and academic achievement (Möller et al. 2009). This is consistent with the early works in elementary education by Ehm et al. (2014) and Pinxten et al. (2015). Specifically, when we analyzed the classic I/E model, negative paths from math achievement to reading self-concept as well as from reading achievement to math self-concept in German grade 3 students was found (Ehm et al. 2014). When we examined the I/E model and the BFLP model simultaneously, math achievement positively predicted math self-concept and negatively predicted their verbal (Dutch) self-concept in grade 4 students (Pinxten et al. 2015).

Unexpectedly, the correlation analysis results prove that Chinese self-concept was negatively correlated with Chinese grade but was closely positively correlated with 
Table 3 Tests of interpersonal and intergroup upward social comparison

\begin{tabular}{|c|c|c|c|c|}
\hline \multirow[t]{2}{*}{ Variable } & \multicolumn{2}{|l|}{ Majority Group } & \multicolumn{2}{|l|}{ Minority Group } \\
\hline & $\begin{array}{l}\text { Model } 3 \\
\beta(\mathrm{SE})\end{array}$ & $\begin{array}{l}\text { Model } 4 \\
\beta(\mathrm{SE})\end{array}$ & $\begin{array}{l}\text { Model } 5 \\
\beta(\mathrm{SE})\end{array}$ & $\begin{array}{l}\text { Model } 6 \\
\beta(\mathrm{SE})\end{array}$ \\
\hline \multicolumn{5}{|l|}{ Fixed Effect } \\
\hline \multicolumn{5}{|l|}{ Level 1: Individual variables } \\
\hline Gender & $0.114(0.062)$ & $0.097(0.056)$ & $0.035(0.094)$ & $0.140(0.108)$ \\
\hline Age & $-0.131^{* * * *}(0.027)$ & $-0.113^{* * *}(0.026)$ & $0.072(0.056)$ & $0.057(0.053)$ \\
\hline Parents' Socioeconomic Status & $0.007(0.004)$ & $0.003(0.004)$ & $0.006(0.007)$ & $0.009(0.006)$ \\
\hline Mathematics Grade & $0.311^{* * * *}(0.057)$ & $0.265^{* * *}(0.059)$ & $0.265(0.059)$ & $0.159^{* *}(0.058)$ \\
\hline Chinese Grade & $-0.093^{*}(0.046)$ & $-0.057(0.042)$ & $-0.089(0.068)$ & $-0.042(0.051)$ \\
\hline \multicolumn{5}{|l|}{ Level 2: Class-level variables } \\
\hline CA-MG & $0.296(1.390)$ & $-0.096(0.294)$ & $-1.399(0.803)$ & $2.568(0.966)$ \\
\hline LBCA-MG & $-0.123(1.365)$ & & $0.601(0.616)$ & \\
\hline NLBCA-MG & & $0.117(0.196)$ & & $-3.240^{*}(1.143)$ \\
\hline \multicolumn{5}{|l|}{ Random Effect } \\
\hline $\operatorname{Intercepts}\left(\tau_{00}\right)$ & $0.094^{* * * *}$ & $0.077^{* * * *}$ & $0.289^{* * * *}$ & $0.165^{* * * *}$ \\
\hline $\operatorname{Residual}\left(\sigma^{2}\right)$ & 0.237 & 0.272 & 0.227 & 0.222 \\
\hline \multicolumn{5}{|l|}{ Model summary } \\
\hline Deviance(-2LL) & 426.502 & 529.979 & 213.753 & 202.006 \\
\hline
\end{tabular}

$\beta$ is the unstandardized regression coefficient. Control variables are gender, age, parents' socioeconomic status, mathematics grade, and Chinese grade at Level 1

CA-MG at Level 2

$C A-M G$ Class-average mathematics grade, $L B C A-M G$ Left-behind children-average mathematics grade, $N L B C A$ $M G$ Non-left-behind children-average mathematics grade

[Majority group (Model 3 Upward Interpersonal Comparison: Individual-level variables, $n=268$; Class-level variables, $n=23$. Model 4 Upward Intergroup Comparison: Individual-level variables, $n=311$; Class-level variables, $\mathrm{n}=23$ )]; [Minority group (Model 5 Upward Interpersonal Comparison: Individual-level variables, $n=121$; Class-level variables, $n=21$. Model 6 Upward Intergroup Comparison: Individual-level variables, $n=120$; Classlevel variables, $n=19)$ ]

${ }^{*} p<0.05 ;{ }^{* *} p<0.01 ;{ }^{* * *} p<0.001$

mathematics self-concept. The possible reason for the differences may be related to the elementary schoolaged children of the present study. At this stage of mental development, children typically encounter difficulties in differentiating between actual and desired attributes (Harter 1999). Therefore, their self-evaluations are likely to be very positive but, unfortunately, also unrealistic (Eccles et al. 1993; Helmke 1999). In the case of left-behind children, this gets combined with their immature physical and mental development. Leftbehind children experience more physical and behavioral problems in China, such as physical developmental delays (Zhang et al. 2015). In terms of educational performance, parental migration is harmful to the development of cognitive ability in children in India and Vietnam (Nguyen 2016). Thus, the ability of judgment, perception, and self-perception of left-behind children still need to be improved (Cui 2009). Therefore, when evaluating the self-concept of Chinese and mathematics, low-consistency evaluations may occur.
Furthermore, social comparison and its effects observed in this study were different from those reported in previous studies on the BFLPE. The results based on the collected data demonstrate that the formation of the mathematics self-concept was different among leftbehind children when they were the majority group members and the minority group members in the class. When left-behind children were the majority group, the results were partially consistent with Hypothesis 2. The assimilation effect within this group was significant in downward comparison, indicating that left-behind children had a lower level of mathematics self-concept when they entered the class with lower than average mathematics achievement. For the left-behind children as the minority group, the results were partially consistent with Hypothesis 3. The contrast effect was reflected through the observation that the higher the average mathematics achievement of non-left-behind children, the lower the mathematics self-concept of left-behind children. 
Table 4 Tests of interpersonal and intergroup downward social comparison

\begin{tabular}{|c|c|c|c|c|}
\hline \multirow[t]{2}{*}{ Variable } & \multicolumn{2}{|l|}{ Majority Group } & \multicolumn{2}{|l|}{ Minority Group } \\
\hline & $\begin{array}{l}\text { Model } 7 \\
\beta(\mathrm{SE})\end{array}$ & $\begin{array}{l}\text { Model } 8 \\
\beta(\mathrm{SE})\end{array}$ & $\begin{array}{l}\text { Model } 9 \\
\beta(\mathrm{SE})\end{array}$ & $\begin{array}{l}\text { Model } 10 \\
\beta(\mathrm{SE})\end{array}$ \\
\hline \multicolumn{5}{|l|}{ Fixed Effect } \\
\hline \multicolumn{5}{|l|}{ Level 1: Individual variables } \\
\hline Gender & $0.092(0.065)$ & $0.122(0.071)$ & $0.212^{* * *}(0.077)$ & $0.157(0.091)$ \\
\hline Age & $-0.059(0.035)$ & $-0.069^{*}(0.035)$ & $-0.004(0.057)$ & $-0.033(0.055)$ \\
\hline Parents' Socioeconomic Status & $0.003(0.004)$ & $0.004(0.005)$ & $0.006(0.007)$ & $0.004(0.007)$ \\
\hline Mathematics Grade & $0.357^{* * *}(0.101)$ & $0.387^{* *}(0.110)$ & $0.272(0.200)$ & $0.768^{*}(0.336)$ \\
\hline Chinese Grade & $-0.046(0.065)$ & $-0.031(0.068)$ & $-0.212(0.125)$ & $0.138(0.236)$ \\
\hline \multicolumn{5}{|l|}{ Level 2: Class-level variables } \\
\hline CA-MG & $-1.604^{*}(0.603)$ & $-0.098(0.251)$ & $0.030(0.593)$ & $-0.502(0.932)$ \\
\hline LBCA-MG & $1.449^{*}(0.627)$ & & $0.171(0.409)$ & \\
\hline NLBCA-MG & & $-0.118(0.166)$ & & $0.378(0.999)$ \\
\hline \multicolumn{5}{|l|}{ Random Effect } \\
\hline $\operatorname{Intercepts}\left(\tau_{00}\right)$ & $0.028^{* *}$ & $0.046^{* * * *}$ & $0.045^{*}$ & $0.094^{* *}$ \\
\hline $\operatorname{Residual}\left(\sigma^{2}\right)$ & 0.307 & 0.292 & 0.364 & 0.362 \\
\hline \multicolumn{5}{|l|}{ Model summary } \\
\hline Deviance(-2LL) & 565.698 & 512.073 & 313.369 & 315.125 \\
\hline
\end{tabular}

$\beta$ is the unstandardized regression coefficient. Control variables are gender, age, parents' socioeconomic status, mathematics grade, and Chinese grade at Level 1

CA-MG at Level 2

$C A-M G$ Class-average mathematics grade, $L B C A-M G$ Left-behind children-average mathematics grade, $N L B C A$ $M G$ Non-left-behind children-average mathematics grade

[Majority group (Model 7 Downward Interpersonal Comparison: Individual-level variables, $n=318$; Class-level variables, $\mathrm{n}=23$. Model 8 Downward Intergroup Comparison: Individual-level variables, $n=291$; Class-level variables, $n=23$.)]; [Minority group (Model 9 Downward Interpersonal Comparison: Individual-level variables, $n=157$; Class-level variables, $\mathrm{n}=21$. Model 10 Downward Intergroup Comparison: Individual-level variables, $n=157$; Class-level variables, $n=20)]$

${ }^{*} p<0.05 ;{ }^{* *} p<0.01 ;{ }^{* * *} p<0.001$

\section{Materials and Methods-Study 2}

\section{Participants and Procedure}

Questionnaires were collected from the same sample of leftbehind children who participated in Study 1. After getting consent from the school, left-behind children were asked to complete the questionnaires in the classroom. Their data were collected at T2; the time interval between the two studies was 6 months. A total of 874 questionnaires were distributed. Based on left-behind children's schools, classes, and names, 585 questionnaires could be paired with the original questionnaires in Study 1. The average age of participants was 11.78 $(S D=1.17)$. Within the valid participants, $46.4 \%$ were boys and $50.4 \%$ were girls. The study was approved by the Academic Ethical Group of the Faculty of Education, Soochow University of China. The parents or legal representatives of all the students in the study obtained a written informed parental consent.

\section{Materials}

\section{School Engagement}

School engagement was measured through the Rochester Assessment of Intellectual and Social Engagement (RAISE) (Miserandino 1997), and Cognitive Engagement Questionnaire (Zhang, 2013). The questionnaire consisted of 13 items and 3 subscales, including behavioral engagement (4 items), emotional engagement (5 items), and cognitive engagement (4 items). For example, "I listen carefully in class" (behavioral engagement), "When I'm doing my work in class, I feel interested" (emotional engagement), and "The accuracy of my homework is very high" (cognitive engagement). All 13 items were rated on a 5-point scale, ranging from 1 (completely disagree) to 5 (completely agree). Cronbach's alpha coefficient was 0.796 for all scales, and 0.686 (behavioral engagement), 0.694 (emotional engagement), and 0.638 (cognitive engagement) for the three subscales. 


\section{Mathematics Grade}

Students' mathematics grades were obtained from their own self-assessment of their mathematics scores. A five-grade scale was adopted: 1 (far under the mean), 2 (slightly under the mean), 3 (at the mean), 4 (slightly above the mean), and 5 (far above the mean). A score of 5 represented the best grade, whereas a score of 1 represented the worst grade.

\section{Statistical Analyses}

Given the hierarchical data structure (students nested in classes), we tested Hypotheses 4 and 5 with multilevel structural equation modeling (MSEM) conducted using the Mplus Version 7.4 (Muthén and Muthén 1998-2012) and following the procedure of Preacher et al. (2010, 2011). The multilevel solution allowed decomposition of the variance of Level 1 variables into within and between components and accounted for the fact that relationships might differ between the withingroup and between-group levels. Because all three variables were assessed at the student level, this model could be described as a 1-1-1 multilevel mediation model. Figure 1 depicts how the relationships between mathematics self-concept at $\mathrm{T} 1$ and mathematics achievement are illustrated, which are mediated by mathematics school engagement. As can be seen from Fig. 1, we estimated all paths (within: aw, bw, c'w; between: ab, bb, c'b) at within-group and between-group levels of analysis. We specified random intercepts and fixed slopes. Some researchers discuss this approach as, "Although an MSEM model with all random intercepts and random slopes can be estimated, such a model adds unnecessary complications and may reduce the probability of convergence" (Preacher et al. 2010, p. 217).

\section{Results}

\section{Preliminary Analysis}

Means, standard deviations, and correlations of research variables are listed in Table 5. Correlation analysis shows that $\mathrm{T} 1$ mathematics self-concept was significantly positively related to T2 behavioral engagement ( $r=0.453, p<0.01$ ), T2 emotional engagement $(r=0.521, p<0.01)$, and T2 cognitive engagement $(r=0.475, p<0.01)$. Further, T2 behavioral engagement $(r=0.295, p<0.01)$, T2 emotional engagement $(r=0.330, p<0.01), \mathrm{T} 2$ cognitive engagement $(r=0.344$, $p<0.01$ ) were significantly positively related to $\mathrm{T} 2$ mathematics grade.

\section{Multilevel Mediation Model Analysis}

Relationships between mathematics self-concept at $\mathrm{T} 1$ and mathematics grade at $\mathrm{T} 2$ were analyzed both at within-

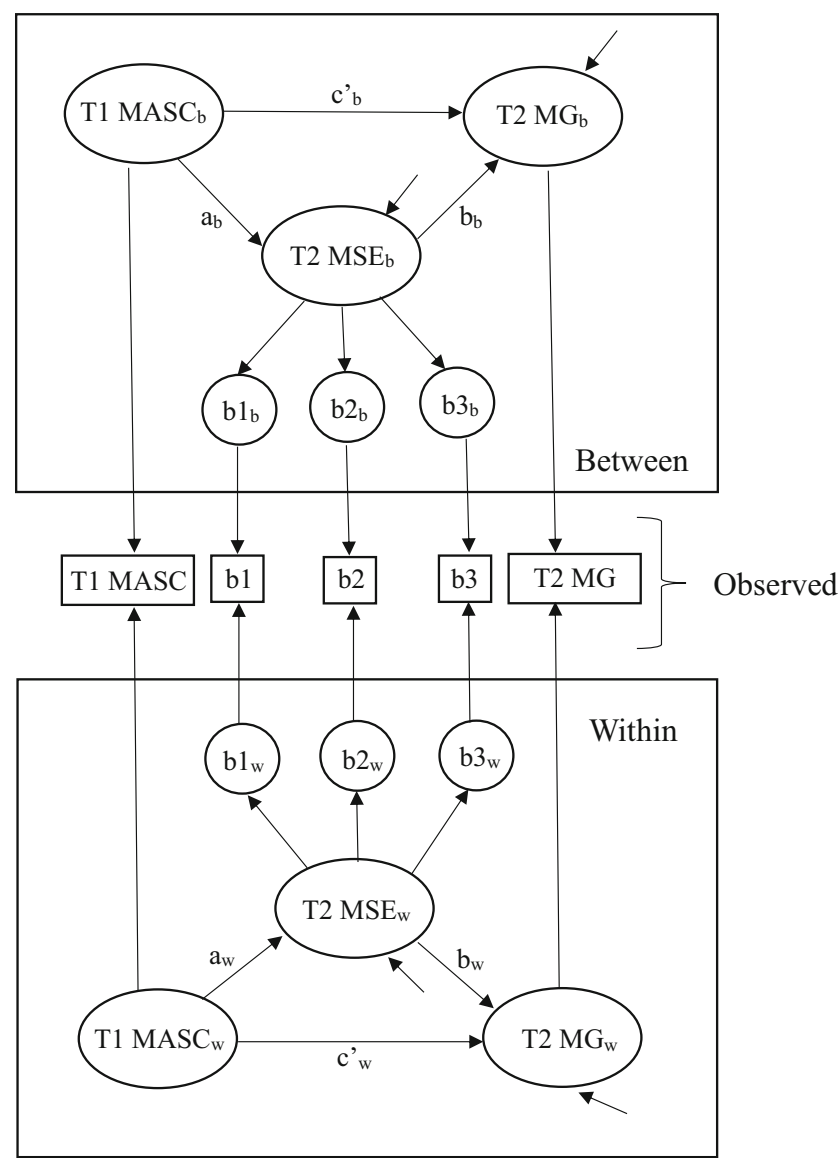

Fig. 1 Multilevel structural equation model depicts a 1-1-1 multilevel mediation model between mathematics self-concept at Time 1 (T1 MASC), mathematics school engagement at Time 2 (T2 MSE) and mathematics grade at Time 2 (T2 MG). Figure is based on Preacher et al. (2011)

group and between-group levels. Results of this multilevel mediation model investigating the effect of mathematics self-concept at $\mathrm{T} 1$ on mathematics grade at $\mathrm{T} 2$ through mathematics school engagement at $\mathrm{T} 2$ are presented in Table 6. At the within-group level, mathematics selfconcept at $\mathrm{T} 1$ was significantly related to mathematics school engagement at T2 (estimate $=0.421, p<0.001)$ and mathematics grade at T2 (estimate $=0.419, p<0.001$ ). Further, the relationships between mathematics school engagement and mathematics grade were also significant (estimate $=0.552, p<0.001)$. Moreover, the within indirect effect through mathematics school engagement at $\mathrm{T} 2$ was significant (estimate $=0.232, p<0.001) 95 \%$ CI $[0.112$, 0.352]. At the between-group level, mathematics selfconcept at $\mathrm{T} 1$ had a significantly direct effect on mathematics school engagement at T2 (estimate $=0.599, p<0.05$ ) but not on mathematics grade at T2 (estimate $=-0.265$, $p>0.05)$. Moreover, the relationship between mathematics school engagement and mathematics grade was not significant (estimate $=0.821, p>0.05$ ). Finally, the between indirect effect through mathematics school engagement at T2 
Table 5 Descriptive statistics and correlations

\begin{tabular}{lllllll}
\hline Variables & Mean & SD & 1 & 2 & 3 & 4 \\
\hline 1. Mathematics Self-concept(T1) & 4.387 & 0.668 & & & & \\
2. Behavioral Engagement(T2) & 4.451 & 0.628 & $0.453^{* * *}$ & & & \\
3. Emotional Engagement(T2) & 3.767 & 0.644 & $0.521^{* *}$ & $0.537^{* *}$ & & \\
4. Cognitive Engagement(T2) & 3.952 & 0.613 & $0.475^{* *}$ & $0.484^{* *}$ & $0.545^{* *}$ & \\
5. Mathematics Grade(T2) & 3.440 & 0.933 & $0.453^{* *}$ & $0.295^{* *}$ & $0.330^{* *}$ & $0.344^{* *}$ \\
${ }^{*} p<0.05 ;{ }^{* *} p<0.01 ;{ }^{* * *} p<0.001$ & & & & & &
\end{tabular}

was not significant (estimate $=0.492, p>0.05), 95 \% \mathrm{CI}$ $[-0.167,1.150]$.

\section{Discussion}

The data revealed that Hypotheses 4 and 5 were partially supported. A comparison of the relationships at the withingroup and between-group levels of analysis revealed notable differences: The relationships between self-concept at $\mathrm{T} 1$ and mathematics achievement at $\mathrm{T} 2$ through mathematics school engagement at T2 were significant at the withingroup level, while they were not significant at the betweengroup level. These results suggest that a student's average level of mathematics self-concept at $\mathrm{T} 1$ plays a predominant role in determining the differences in individual school engagement at $\mathrm{T} 2$ and mathematics achievement at $\mathrm{T} 2$. The

Table 6 Multilevel mediation model predicting mathematics grade from mathematics self-concept at $\mathrm{T} 1$ and mathematics school engagement in study 2

\begin{tabular}{lll}
\hline Variables & Estimate & $\mathrm{SE}$ \\
\hline Level 1: Within-student level & & \\
Path $\mathrm{a}_{\mathrm{w}}:$ T1 MASC $\rightarrow$ T2 MSE & $0.421^{* * * *}$ & 0.035 \\
Path $\mathrm{b}_{\mathrm{w}}:$ T2 MSE $\rightarrow \mathrm{T} 2 \mathrm{MG}$ & $0.552^{* * * *}$ & 0.137 \\
Path c ${ }_{\mathrm{w}}:$ T1 MASC $\rightarrow \mathrm{T} 2 \mathrm{MG}$ & $0.419^{* * * *}$ & 0.084 \\
Indirect effect & $0.232^{* * * *}$ & 0.061 \\
Residual variance T2 MG & $0.653^{* * * *}$ & 0.047 \\
Residual variance T2 MSE & $0.094^{* * *}$ & 0.014 \\
Level 2: Between-student level & & \\
Intercept & 2.446 & 1.371 \\
Path $\mathrm{a}_{\mathrm{b}}:$ T1 MASC $\rightarrow \mathrm{T} 2 \mathrm{MSE}$ & $0.599^{*}$ & 0.275 \\
Path $\mathrm{b}_{\mathrm{b}}$ : T2 MSE $\rightarrow \mathrm{T} 2 \mathrm{MG}$ & 0.821 & 0.443 \\
Path c' ${ }_{\mathrm{b}}:$ T1 MASC $\rightarrow \mathrm{T} 2 \mathrm{MG}$ & -0.265 & 0.393 \\
Indirect effect & 0.492 & 0.336 \\
Residual variance T2 MG & 0.001 & 0.936 \\
Residual variance T2 MSE & $0.007^{*}$ & 0.004 \\
\hline
\end{tabular}

Models are 1-1-1 mediation models with a random intercept and fixed slopes

Path: refer to Fig. 1. $N=52$ at the between-student level

T1 MASC mathematics self-concept at Time 1, T2 MSE mathematics school engagement at Time 2, T2 MG mathematics grade at Time 2

${ }^{*} p<0.05 ;{ }^{* *} p<0.01 ;{ }^{* * *} p<0.001$ class-average level of mathematics self-concept at T1 seemed to be less significant in determining the classaverage level variance in mathematics achievement at $\mathrm{T} 2$.

At the between-group level, mathematics self-concept at $\mathrm{T} 1 \mathrm{had}$ a significantly positive effect on mathematics school engagement at $\mathrm{T} 2$. This result indicates that classes with higher level of mathematics self-concept were more likely to possess higher level of mathematics school engagement. The contextual effect of mathematics selfconcept at $\mathrm{T} 1$ on mathematics school engagement at $\mathrm{T} 2$ was consistent with the motivation model of Connell and Wellborn (1991) on the causal relationship between self and action.

From the relationship between mathematics self-concept at $\mathrm{T} 1$ and mathematics achievement at $\mathrm{T} 2$ at the withingroup level, we could see that the self-enhancement model was verified. This conclusion is consistent with the research results for the same cultural background (Yang 2008; Chen and Shi ., 2016). Mathematics self-concept at T1 affected mathematics achievement at T2 through mathematics school engagement at $\mathrm{T} 2$ at the within-group level, which is also consonant with the sequence of the links in the model of Connell and Wellborn (context-self-action-outcome).

\section{General Discussion}

\section{Formation and Influence Mechanism}

Study 1 aimed to investigate the mechanism in the formation of left-behind children's mathematics self-concept. The main contribution of study 1 was that we tested the existing integrated model of the formation of academic self-concept with a Chinese sample. In this way, this study extended the external generalizability of previous findings and enriched the previous integrated model of the formation of academic self-concept. It also demonstrated the hazards in applying previous research findings to specifically explain the mathematics self-concept formation of left-behind children. The results indicated that the mathematics self-concept of left-behind children was positively predicted by their mathematics achievement but negatively predicted by their Chinese achievement. 
However, this study showed there was no statistically significant effect of class-average mathematics grade on the individual mathematics self-concept of left-behind children.

Another meaningful contribution of the present study 1 was that we broadened the existing academic self-concept literature by emphasizing that changes in the reference groupeven within the same classroom - were related to the formation of academic self-concept. The results suggested that social comparisons had different characteristics in classes with different proportions of left-behind children. For the leftbehind children as the majority group, their average mathematics achievement had a significant positive impact on mathematics self-concept under conditions in which left-behind children compared their mathematics achievement to that of left-behind children whose mathematics achievement was inferior. For the left-behind children as the minority group, the average mathematics achievement of non-left-behind children had a significant negative impact on mathematics self-concept under the conditions in which left-behind children compared their mathematics achievement to that of non-left-behind children whose mathematics achievement was superior. These results reflected the uniqueness of the formation of leftbehind children's mathematics self-concept.

As an important predictive variable of educational results, academic self-concept has definite significance, to some extent. Therefore, to further explore the peculiarities of the influence mechanism of the academic self-concept of leftbehind children, study 2 mainly discussed how the mathematics self-concept of left-behind children at $\mathrm{T} 1$ affected their mathematics achievement at T2 at within-group and between-group levels. Study 2 offered a methodological contribution by employing a longitudinal design and multilevel structural equation modeling to account for the characteristics of the influence mechanism of the mathematics self-concept of left-behind children at the two levels. The results showed that the mathematics self-concept of left-behind children at $\mathrm{T} 1$ had significant effects on their mathematics school engagement at T2 at within-group and between-group levels. Further, the mathematics school engagement of left-behind children at $\mathrm{T} 2$ played a partially mediating role between their mathematics self-concept at $\mathrm{T} 1$ and their mathematics achievement at $\mathrm{T} 2$ at the within-group level.

In summary, we provided a more refined understanding of the development of the mathematics self-concept of leftbehind children in China. Specifically, the present study offered a more detailed look at the formation mechanism of the mathematics self-concept of left-behind children in China, based on an integrated model. The results presented a more meaningful and broader view of the prevailing belief that class-average mathematics achievement had a significant effect on mathematics self-concept in classes. Instead, this study showed that class-average mathematics achievement had no significant effect on mathematics self-concept in classes with different proportions of left-behind children. In this study, different social comparisons were divided into interpersonal social comparison and intergroup social comparison in the classes that included subgroups. We found that there were assimilation effects, meaning, as discussed above, that left-behind children would have a lower level of mathematics self-concept if they were in classes with lower average mathematics achievement of left-behind children. We also found that there were contrast effects, meaning that those who entered classes with higher average mathematics achievement of non-leftbehind children would have a lower level of mathematics self-concept. The findings of this research highlighted that the influence mechanism of the mathematics self-concept of left-behind children did exist. Notably, mathematics school engagement at $\mathrm{T} 2$ actually mediated the relationship between the mathematics self-concept of left-behind children at $\mathrm{T} 1$ and their mathematics achievement at $\mathrm{T} 2$ at the within-group level, and the self-enhancement model at the within-group level provided a kind of support for the influence mechanism of the mathematics self-concept of left-behind children.

\section{Implication for Educational Research and Practice}

The present study has some useful implications for school principals, teachers, and students. First, the results of this study showed that academic achievement within a domain could promote academic self-concept in the same domain (mathematics achievement on mathematics self-concept). Furthermore, academic achievement in a domain might not have the effect to improve academic self-concept in a different domain that is of different nature and demands a different learning process (Chinese achievement on mathematics self-concept). The common explanation for this phenomenon is that positive mathematics self-concept encourages students to devote more energy to mathematics learning, and correspondingly, less effort is devoted to Chinese or other domains. There appears to be a need for teachers to consolidate and strengthen students' knowledge and ability in the process of teaching, to form specific academic selfconcept different from that in other domains. Moreover, teachers should also give cognitive and emotional support to the students' weak domains to reduce the sense of imbalance of self-concept in different domains.

School principals and teachers should note that left-behind children tend to make negative social comparisons, which may be closely related to their negative self-assessment and self-identity. Therefore, the construction of a supportive and harmonious scientific education environment is key to improve the selfconcept of left-behind children's academic self-concept. In daily teaching practice, teachers should pay more attention to their emotional experience and make them feel respected and accepted. Thus, some left-behind children who have made great efforts in their studies and achieved stable achievement should be 
commended, so that others can be inspired and have a broader reference standard.

The multilevel mediation model highlights a strong effect of students' school engagement on academic achievement. In other words, what students need is not only sound and positive academic self-concept but their engagement in school. Wolters (2003) believed that school engagement could be viewed as a dimension of learning that could be regulated by the students themselves. Therefore, to achieve the optimal results of academic development, good behavior patterns should be established. The implications of the major results of this study may give some insights to school principals and teachers who intend to help students develop appropriate academic self-concept and attain ideal academic development.

\section{Limitations of the Present Study}

There are several limitations of the present study that should be considered. First, this study only investigated the formation and influence mechanism of academic selfconcept of left-behind children in mathematics. Although academic self-concept of mathematics is representative, actually, academic self-concept is a hierarchical and multidimensional concept, including multidisciplinary academic self-concept in different disciplines (such as Chinese, mathematics, etc.). In addition, there are differences in knowledge content and knowledge form among different disciplines, so the corresponding ways to form academic selfconcept have their own characteristics. Future studies could explore the academic self-concept of multiple disciplines, using different approaches, providing sufficient and comprehensive evidences for the formation of left-behind children's academic self-concept.

Second, the present research only investigated leftbehind children at Time 2, which is an important limitation of the present study. Due to the lack of data of non-leftbehind children at Time 2, potential differences between mathematics self-concept of left-behind children and its influence on mathematics achievements, and that of nonleft-behind cannot be explored. Considering that leftbehind children have been seen as a vulnerable group, the results of Time 2 cannot be generalized to China in general. Future research could run tracking studies that includes both left-behind children and non-left-behind children, increasing the generalization of the interpretation of present results at Time 2 .

Third, Study 2 investigated the mechanism of mathematics self-concept at T1 on mathematics achievement at T2. Mathematics school engagement partially explained the relationship between mathematics self-concept at $\mathrm{T} 1$ and mathematics achievement at T2; it may be theorized that other motivational processes played a role (e.g. selfefficacy beliefs). Additionally, contextual influence on mathematics school engagement at T2 and mathematics achievement at T2 are not yet clear. In a model by Connell et al. (1994), external context (such as parents' educational participation, social support, etc.) played an important role in changing individual behavior and result. Therefore, the influence of different school situations or family environments on individual academic outcomes need to be further studied.

Fourth, different measures of academic achievement would affect the relationship between academic selfconcept and academic achievement. For example, the differences between academic grades and standardized test scores have been discussed (Marsh 1987; Marsh et al. 2018). To identify the relationship between mathematics self-concept and mathematics achievement, follow-up studies should evaluate how and to what extent that left-behind children's academic achievement and academic selfconcept at T1 effect their academic achievement and academic self-concept at T2 through different measurement methods. Alternatively, we could also adopt a crosslagged research method to verify the interaction between academic self-concept and academic achievement.

Finally, we used the method of pre-test and post-test to track academic self-concept and academic achievement. It was not a repeated measurement of the main variables at Time 1 and Time 2, but other variables were also applied at Time 2. It would be better for future research to have the same scales at each instance of examination. Furthermore, the time span between the tracking studies was only 6 months and the result is not consistent with the findings of Skaalvik and Valas (1999). The possible reasons for the differences may due to the differences in the tracking time. It is suggested that future studies should increase the time span between tracking studies, and should increase the number of such studies. For example, repeat all measurements a third time after 2 years to better understand the growth trajectory of academic self-concept of left-behind children.

\section{Conclusions}

The present study contributes to research on academic selfconcept in several ways. This study helps clarify the formation mechanism of mathematics self-concept of left-behind children in mainland China. The results of study 1 were not total consistent with the combined (the I/E model and the BFLPE) model. Specifically, the I/E model was supported partially, whereas the BFLPE was invalid when interpersonal or intergroup comparison process has been engaged in social comparisons. Furthermore, it is one of the first testing influence mechanism of mathematics self-concept with multilevel structural equation modeling. The results of study 2 suggested that the indirect effects of mathematics self-concept at Time 1 on 
mathematics achievement at Time 2 mainly focus on the within-group level. Hence, the results indicate that contextualized characteristics may play a role in the formation and influence mechanism of mathematics self-concept of leftbehind children. Based on these conclusions, we suggest that future research on the academic self-concept should incorporate in- and out- group as a contextual variable in the social comparison model and to consider hierarchical data structure of the sample in order to get a precise influence mechanism of academic self-concept.

Funding Information This study was funded by the National Natural Science Foundation of China (71473173) and Postgraduate Research \& Practice Innovation Program of Jiangsu Province (KYCX17_1961).

\section{Compliance with Ethical Standards}

Conflict of Interest The authors declare that they have no conflict of interest.

Ethical Approval All procedures performed in studies involving human participants were in accordance with the ethical standards of the institutional research committee and with the 1964 Helsinki declaration and its later amendments or comparable ethical standards.

Informed Consent Informed consent was obtained from all individual participants included in the study.

\section{Appendix 1}

Presentation of all parameter estimates includes Chinese selfconcept as a control variable in Table 7, Table 8 and Table 9

Table 7 Tests of combined model

\begin{tabular}{|c|c|c|c|}
\hline \multirow[t]{2}{*}{ Variable } & Model 1 & \multicolumn{2}{|l|}{ Model 2} \\
\hline & SE & $\beta$ & SE \\
\hline \multicolumn{4}{|l|}{ Fixed Effect } \\
\hline \multicolumn{4}{|l|}{ Level1:Individual variables } \\
\hline Gender & & $0.210^{* *}$ & 0.030 \\
\hline Age & & $-0.033^{*}$ & 0.014 \\
\hline Parents' Socioeconomic Status & & -0.002 & 0.002 \\
\hline Mathematics Grade & & $0.207^{* * * *}$ & 0.024 \\
\hline Chinese Grade & & $-0.050^{*}$ & 0.023 \\
\hline Chinese self-concept & & 0.530 & 0.023 \\
\hline \multicolumn{4}{|l|}{ Level2:Class-level variables } \\
\hline CA-MG & & -0.048 & 0.075 \\
\hline \multicolumn{4}{|l|}{ Random Effect } \\
\hline $\operatorname{Intercepts}\left(\tau_{00}\right)$ & $0.095^{* * *}$ & $0.022^{* * * *}$ & \\
\hline $\operatorname{Residual}\left(\sigma^{2}\right)$ & 0.389 & 0.160 & \\
\hline \multicolumn{4}{|l|}{ Model summary } \\
\hline Deviance(-2LL) & 1732.489 & 973.751 & \\
\hline
\end{tabular}

$\beta$ is the unstandardized regression coefficient

Control variables are gender, age, parents' socioeconomic status and Chinese self-concept at Level 1

$C A-M G$ Class-average mathematics grade

${ }^{*} p<0.05 ;{ }^{* *} p<0.01 ;{ }^{* * *} p<0.001$ 
Table 8 Tests of interpersonal and intergroup upward social comparison

\begin{tabular}{|c|c|c|c|c|}
\hline \multirow[t]{2}{*}{ Variable } & \multicolumn{2}{|l|}{ Majority Group } & \multicolumn{2}{|l|}{ Minority Group } \\
\hline & $\begin{array}{l}\text { Model } 3 \\
\beta(\mathrm{SE})\end{array}$ & $\begin{array}{l}\text { Model } 4 \\
\beta(\mathrm{SE})\end{array}$ & $\begin{array}{l}\text { Model } 5 \\
\beta(\mathrm{SE})\end{array}$ & $\begin{array}{l}\text { Model } 6 \\
\beta(\mathrm{SE})\end{array}$ \\
\hline \multicolumn{5}{|l|}{ Fixed Effect } \\
\hline \multicolumn{5}{|l|}{ Level1:Individual variables } \\
\hline Gender & $0.205^{* * *}(0.052)$ & $0.211^{* * * *}(0.047)$ & $0.190^{* *}(0.068)$ & $0.234^{* *}(0.076)$ \\
\hline Age & $-0.091^{* * * *}(0.023)$ & $-0.076^{* * * *}(0.020)$ & $0.059(0.043)$ & $0.022(0.047)$ \\
\hline Parents' Socioeconomic Status & $0.005(0.004)$ & $0.004(0.004)$ & $-0.003(0.004)$ & $0.002(0.005)$ \\
\hline Mathematics Grade & $0.261^{* * * *}(0.048)$ & $0.253^{* * * *}(0.045)$ & $0.073(0.087)$ & $0.127(0.067)$ \\
\hline Chinese Grade & $-0.057(0.037)$ & $-0.034(0.034)$ & $-0.089(0.063)$ & $-0.042(0.049)$ \\
\hline Chinese self-concept & $0.447^{* * * *}(0.031)$ & $0.488^{* * * *}(0.035)$ & $0.456^{* * *}(0.057)$ & $0.424^{* * * *}(0.047)$ \\
\hline \multicolumn{5}{|l|}{ Level2:Class-level variables } \\
\hline CA-MG & $-0.437(0.902)$ & $-0.079(0.258)$ & $-0.638(0.370)$ & $1.862^{*}(0.831)$ \\
\hline LBCA-MG & $0.500(0.886)$ & & $0.263(0.367)$ & \\
\hline NLBCA-MG & & $0.040(0.184)$ & & $-2.094^{*}(0.850)$ \\
\hline \multicolumn{5}{|l|}{ Random Effect } \\
\hline $\operatorname{Intercepts}\left(\tau_{00}\right)$ & $0.050^{* * * *}$ & $0.039^{* * * *}$ & $0.111^{* * * *}$ & $0.069^{* * *}$ \\
\hline $\operatorname{Residual}\left(\sigma^{2}\right)$ & 0.143 & 0.153 & 0.144 & 0.144 \\
\hline \multicolumn{5}{|l|}{ Model summary } \\
\hline Deviance(-2LL) & 296.597 & 360.173 & 16.503 & 150.167 \\
\hline
\end{tabular}

$\beta$ is the unstandardized regression coefficient

Control variables are gender, age, parents' socioeconomic status, mathematics grade, Chinese grade and Chinese self-concept at Level 1, CA-MG at Level 2

$C A-M G$ Class-average mathematics grade, $L B C A-M G$ Left-behind children-average mathematics grade, $N L B C A$ $M G$ Non-left-behind children-average mathematics grade

[Majority group (Model3 Upward Interpersonal Comparison: Individual-level variables, $\mathrm{n}=268$; Class-level variables, $\mathrm{n}=23$. Model4 Upward Intergroup Comparison: Individual-level variables, $\mathrm{n}=311$; Class-level variables, $n=23$ )]; [Minority group (Model5 Upward Interpersonal Comparison: Individual-level variables, $\mathrm{n}=121$; Class-level variables, $\mathrm{n}=21$. Model6 Upward Intergroup Comparison: Individual-level variables, $\mathrm{n}=120$; Classlevel variables, $\mathrm{n}=19)$ ]

${ }^{*} p<0.05 ;{ }^{* *} p<0.01 ;{ }^{* * *} p<0.001$ 
Table 9 Tests of interpersonal and intergroup downward social comparison

\begin{tabular}{|c|c|c|c|c|}
\hline \multirow[t]{2}{*}{ Variable } & \multicolumn{2}{|l|}{ Majority Group } & \multicolumn{2}{|l|}{ Minority Group } \\
\hline & $\begin{array}{l}\text { Model } 7 \\
\beta(\mathrm{SE})\end{array}$ & $\begin{array}{l}\text { Model } 8 \\
\beta(\mathrm{SE})\end{array}$ & $\begin{array}{l}\text { Model } 9 \\
\beta(\mathrm{SE})\end{array}$ & $\begin{array}{l}\text { Model } 10 \\
\beta(\mathrm{SE})\end{array}$ \\
\hline \multicolumn{5}{|l|}{ Fixed Effect } \\
\hline \multicolumn{5}{|l|}{ Level1:Individual variables } \\
\hline Gender & $0.172^{* * *}(0.034)$ & $0.175^{* * *}(0.044)$ & $0.245^{* * * *}(0.058)$ & $0.267^{* * * *}(0.048)$ \\
\hline Age & $0.001(0.015)$ & $-0.007(0.017)$ & $-0.022(0.047)$ & $-0.079(0.049)$ \\
\hline Parents' Socioeconomic Status & $-0.001(0.003)$ & $-0.001(0.003)$ & $-0.003(0.009)$ & $-0.012(0.007)$ \\
\hline Mathematics Grade & $0.269^{* * * *}(0.050)$ & $0.303^{* * * *}(0.069)$ & $0.257(0.169)$ & $0.638^{\text {**** }}(0.139)$ \\
\hline Chinese Grade & $0.012(0.027)$ & $0.012(0.026)$ & $-0.098(0.119)$ & $0.202(0.128)$ \\
\hline Chinese self-concept & $0.573^{* * * *}(0.032)$ & $0.559^{* * * *}(0.035)$ & $0.472^{* * * *}(0.065)$ & $0.655^{* * * *}(0.056)$ \\
\hline \multicolumn{5}{|l|}{ Level2:Class-level variables } \\
\hline CA-MG & $-0.953^{* * *}(0.259)$ & $-0.225(0.158)$ & $-0.019(0.407)$ & $-0.139(0.368)$ \\
\hline LBCA-MG & $0.796^{* *}(0.269)$ & & $0.079(0.286)$ & \\
\hline NLBCA-MG & & $0.031(0.096)$ & & $-0.079(0.499)$ \\
\hline \multicolumn{5}{|l|}{ Random Effect } \\
\hline $\operatorname{Intercepts}\left(\tau_{00}\right)$ & 0.005 & $0.012^{*}$ & $0.031^{*}$ & $0.046^{* * *}$ \\
\hline $\operatorname{Residual}\left(\sigma^{2}\right)$ & 0.149 & 0.150 & 0.245 & 0.134 \\
\hline \multicolumn{5}{|l|}{ Model summary } \\
\hline Deviance(-2LL) & 336.473 & 321.840 & 259.265 & 175.344 \\
\hline
\end{tabular}

$\beta$ is the unstandardized regression coefficient

Control variables are gender, age, parents' socioeconomic status, mathematics grade, Chinese grade and Chinese self-concept at Level 1, CA-MG at Level 2

$C A-M G$ Class-average mathematics grade, $L B C A-M G$ Left-behind children-average mathematics grade, $N L B C A$ $M G$ Non-left-behind children-average mathematics grade

[Majority group (Model7 Downward Interpersonal Comparison: Individual-level variables, $\mathrm{n}=318$; Class-level variables, $\mathrm{n}=23$. Model8 Downward Intergroup Comparison: Individual-level variables, $\mathrm{n}=291$; Class-level variables, $n=23$.)]; [Minority group (Mode19 Downward Interpersonal Comparison: Individual-level variables, $\mathrm{n}=157$; Class-level variables, $\mathrm{n}=21$. Model10 Downward Intergroup Comparison: Individual-level variables, $\mathrm{n}=157$; Class-level variables, $n=20)]$

${ }^{*} p<0.05 ;{ }^{* *} p<0.01 ;{ }^{* * *} p<0.001$
Open Access This article is distributed under the terms of the Creative Commons Attribution 4.0 International License (http:// creativecommons.org/licenses/by/4.0/), which permits unrestricted use, distribution, and reproduction in any medium, provided you give appropriate credit to the original author(s) and the source, provide a link to the Creative Commons license, and indicate if changes were made.

\section{References}

Ai, H., \& Hu, J. (2016). Psychological resilience moderates the impact of social support on loneliness of "left-behind" children. J. Health Psychology, 21, 1066-1073. https://doi.org/10.1177/ 1359105314544992.

Alexander, K. L., Entwisle, D. R., \& Dauber, S. L. (1993). First-grade classroom behavior: Its short- and long-term consequences for school performance. Child Development, 64, 801-814.

Bai, Y., Zhang, L., Liu, C., Shi, Y., Mo, D., \& Rozelle, S. (2018). Effect of parental migration on the academic performance of left behind children in north western China. The Journal of Development Studies, 54(7), 1154-1170. https://doi.org/10.1080/00220388.2017. 1333108.
Boekarts, M., Pintrich, P. R., \& Zeidner, M. (Eds.). (2000). Handbook of self-regulation: Theory, research and applications. San Diego, CA: Academic Press.

Bradley, R. H., \& Corwyn, R. F. (2002). Socioeconomic status and child development. Annual Review of Psychology, 53, 371-399.

Brewer, M. B. (1991). The social self: On being the same and different at the same time. Personality and Social Psychology Bulletin, 17(5), 475-482.

Brewer, M. B., \& Weber, J. G. (1994). Self-evaluation effects of interpersonal versus intergroup social comparison. Journal of Personality and Social Psychology, 66(2), 268-275.

Buhs, E. S. (2005). Peer rejection, negative peer treatment, and school adjustment: Self-concept and classroom engagement as mediating processes. Journal of School Psychology, 43(5), 407-424.

Byrne, B. M. (1996). Academic self-concept: Its structure, measurement, and relation to academic achievement. In B. A. Bracken (Ed.), Handbook of self-concept (pp. 287-316). New York: Wiley.

Calsyn, R. J., \& Kenny, D. A. (1977). Self-concept of ability and perceived evaluation of others: Cause or effect of academic achievement? Journal of Educational Psychology, 69, 136-145.

Cetinkaya, S. (2017). Investigation of academic success, self-esteem and academic self-concept in 4th class primary school students. Higher Education Studies, 7(4), 96-110. 
Chen, G. P., \& Cui, L. J. (1997). The using of self-description questionnaire-type II in China. Chinese Journal of Clinical Psychology, 5(2), 78-82.

Chen, B. H., Chiu, W. C., \& Wang, C. C. (2015). The relationship among academic self-concept, learning strategies, and academic achievement: A case study of national vocational college students in Taiwan via SEM. The Asia-Pacific Education Researcher, 24(2), 419-431. https://doi.org/10.1007/s40299-014-0194-1.

Chen, X. H., \& Shi, W. D. (2016). Cross-legged regression analysis of relationship between academic self-concept and academic achievement in primary and middle school student: Test of reciprocal effect model and development perspective. Psychological Development and Education, 32(1), 81-88. https://doi.org/10.16187/j.cnki. issn1001-4918.2016.01.11

Chiu, M. M., \& Klassen, R. M. (2010). Relations of mathematics selfconcept and its calibration with mathematics achievement: Cultural differences among fifteen-year-olds in 34 countries. Learning and Instruction, 20, 2-17.

Chiu, M. S. (2012). The internal/external frame of reference model, bigfish-little pond effect, and combined model for mathematics and science. Journal of Educational Psychology, 104(1), 87-107.

Chmielewski, A. K., Dumont, H., \& Trautwein, U. (2013). Tracking effects depend on tracking type: An international comparison of students' mathematics self-concept. American Educational Research Journal, 50(5), 925-957. https://doi.org/10.3102/ 0002831213489843.

Cialdini, R. B., Borden, R. J., Thorne, A., Walker, M. R., Freeman, S., \& Sloan, L. R. (1976). Basking in reflected glory: Three (football) field studies. Journal of Personality and Social Psychology, 34, 366-375. https://doi.org/10.1037/0022-3514.34.3.366.

Connell, J. P., \& Wellborn, J. G. (1991). Competence, autonomy, and relatedness: A motivational analysis of self-esteem processes. In M. R. Gunnar, and L. A. Sroufe (Eds.), The minnesota symposia on child development. Self-processes and development (pp. 43-77). Hillsdale, N. J.7 Lawrence Erlbaum and Associates.

Connell, J. P., Spencer, M. B., \& Aber, J. L. (1994). Educational risk and resilience in African-American youth: Context, self, action, and outcomes in school. Child Development, 65(2), 493-506.

Cortes, P. (2015). The feminization of international migration and its effects on the children left behind: Evidence from the Philippines. World Development, 65, 62-78. https://doi.org/10.1016/j.worlddev. 2013.10.021

Covarrubias, R., \& Fryberg, S. A. (2015). The impact of self-relevant representations on school belonging for native American students. Cultural Diversity and Ethnic Minority Psychology, 21, 10-18. https://doi.org/10.1037/a0037819.

Cui, W. J. (2009). Study on the psychological development of left-behind children and its influencing factors. Shanghai Research on Education, 4, 36-38.

Cvencek, D., Nasir, N. S., O'Connor, K., Wischnia, S., \& Meltzoff, A. N. (2015). The development of math-race stereotypes: "They say Chinese people are the best at math". Journal of Research on Adolescence, 25, 630-637. https://doi.org/10.1111/jora.12151.

Duan, C. R., Lai, M. H., \& Qin, M. (2017). Research on the change trend of left-behind children in rural China since the 21st century. China Youth Study, 6, 52-60. https://doi.org/10.19633/j.cnki.11-2579/d. 2017.06.009.

Dumont, H., Protsch, P., Jansen, M., \& Becker, M. (2017). Fish swimming into the ocean: How tracking relates to students' self-beliefs and school disengagement at the end of schooling. Journal of Educational Psychology, 109, 855-870. https://doi.org/10.1037/ edu0000175.

Eccles, J., Wigfield, A., Harold, R. D., \& Blumenfeld, P. (1993). Age and gender differences in children's selfand task perceptions during elementary. Child Development, 64, 830-847.
Ehm, J. H., Lindberg, S., \& Hasselhorn, M. (2014). Reading, writing, and math self-concept in elementary school children: Influence of dimensional comparison processes. European Journal of Psychology of Education, 29(2), 277-294.

European Commission. (2011). Mathematics education in Europe: Common challenges and national policies. Brussels: Education, Audiovisual and Cultural Executive Agency, Eurydice.

Fan, F., Su, L., Gill, M. K., \& Birmaher, B. (2010). Emotional and behavioral problems of Chinese left-behind children: A preliminary study. Social Psychiatry and Psychiatric Epidemiology, 45, 655664. https://doi.org/10.1007/s00127-009-0107-4.

Finn, J. D. (1989). Withdrawing from school. Review of Educational Research, 59(2), 117-142.

Fredricks, J. A., Blumenfeld, P. C., \& Paris, A. H. (2004). School engagement: Potential of the concept, state of the evidence. Review of Educational Research, 74(1), 59-109.

Fryberg, S. A., \& Townsend, S. S. M. (2008). The psychology of invisibility. In G. Adams, M. Biernat, N. R. Branscombe, C. S. Crandall, \& L. S. Wrightsman (Eds.), Commemorating Brown: The social psychology of racism and discrimination (pp. 173-193). Washington, DC: American Psychological Association.

Fu, M., Bo, W. V., Xue, Y., \& Yuan, T. F. (2017). Parental absence accompanies worse academic achievements: Evidence based upon a sample of left-behind children in rural China. Frontiers in Education, 2, 1-7.

Gao, Y., Li, L. P., Kim, J. H., Congdon, N., Lau, J., \& Griffiths, S. (2010). The impact of parental migration on health status and health behaviours among left behind adolescent school children in China. BMC Public Health, 10, 1-10. https://doi.org/10.1186/1471-2458-10-56.

Glanville, J. L., \& Wildhagen, T. (2007). The measurement of school engagement: Assessing dimensionality and measurement invariance across race and ethnicity. Educational and Psychological Measurement, 67(6), 1019-1041.

Gu, S. Z., Yi, S. C., \& Li, H. (2011). Problems and countermeasures on the left-behind children in the course of urbanization. Educational Research, 9, 29-33.

Harter, S. (1999). The construction of the self: A developmental perspective. New York: Guilford.

He, B., Fan, J., Liu, N., Li, H., Wang, Y., Williams, J., \& Wong, K. (2012). Depression risk of 'left-behind children' in rural China. Psychiatry Research, 200, 306-312. https://doi.org/10.1016/j. psychres.2012.04.001.

Helmke, A. (1999). From optimism to realism? Development of children's academic self-concept from kindergarten to grade six. In W. Schneider \& F. E. Weinert (Eds.), Individual development from 3 to 12. Munich Longitudinal Study (pp. 198-221). Cambridge: Cambridge University Press.

Herrmann, J., Schmidt, I., Kessels, U., \& Preckel, F. (2015). Big fish in big ponds: Contrast and assimilation effects on math and verbal selfconcepts of students in within-school gifted tracks. British Journal of Educational Psychology, 86(2), 222-240. https://doi.org/10.1111/ bjep. 12100.

Hu, H., Lu, S., \& Huang, C.-C. (2014). The psychological and behavioral outcomes of migrant and left-behind children in China. Children and Youth Services Review, 46, 1-10. https://doi.org/10.1016/j. childyouth.2014.07.021.

Huguet, P., Dumas, F., Marsh, H., Régner, I., Wheeler, L., Suls, J., . . .Nezlek, J (2009). Clarifying the role of social comparison in the bigfish-little-pond effect (BFLPE): An integrative study. Journal of Personality and Social Psychology, 97, 156-170. https://doi.org/ 10.1037/a0015558.

Hyde, J. S., Fennema, E., \& Lamon, S. J. (1990). Gender differences in mathematics performance: A meta-analysis. Psychological Bulletin, $107(2), 139-155$.

Jia, Z., \& Tian, W. (2010). Loneliness of left-behind children: A crosssectional survey in a sample of rural China. Child: Care, Health and 
Development, 36, 812-817. https://doi.org/10.1111/j.1365-2214. 2010.01110.x.

Karakolidis, A., Pitsia, V., \& Emvalotis, A. (2016). Examining students' achievement in mathematics: A multilevel analysis of the Programme for international student assessment (PISA) 2012 data for Greece. International Journal of Educational Research, 79, $106-115$.

Knigge, M., \& Hannover, B. (2011). Collective school-type identity: Predicting students' motivation beyond academic self-concept. International Journal of Psychology, 46, 191-205. https://doi.org/ 10.1080/00207594.2010.529907.

Köller, O., Trautwein, U., Lüdtke, O., \& Baumert, J. (2006). The interplay of academic achievement, self-concept and interest in the upper secondary school. Z. Pädagog. Psychol., 20, 27-39. https://doi. org/10.1024/1010-0652.20.12.27

Li, L., Wang, L., \& Nie, J. (2017). Effect of parental migration on the academic performance of left-behind middle school students in rural China. China \& World Economy, 25(2), 45-59.

Liou, P. Y. (2014). Investigation of the big-fish-little-pond effect on students' self-concept of learning mathematics and science in Taiwan: Results from TIMSS 2011. Asia-Pacific Education Researcher, 23, 769-778.

Liu, Z., Yu, L., \& Zheng, X. (2017). No longer left-behind: The impact of return migrant parents on children's performance. China Economic Review, 49, 184-196.

Luo, J., Wang, L. G., \& Gao, W. B. (2012). The influence of the absence of fathers and the timing of separation on anxiety and self-esteem of adolescents: A cross-sectional survey. Child: Care, Health and Development, 38(5), 723-731.

Marks, H. M. (2000). Student engagement in instructional activity: Patterns in the elementary, middle, and high school years. American Educational Research Journal, 37, 153-184.

Marsh, H. W. (1986). Verbal and math self-concepts: An internal/external frame of reference model. American Educational Research Journal, 23(1), 129-149.

Marsh, H. W. (1987). The big-fish-little-pond effect on academic selfconcept. Journal of Educational Psychology, 79, 280-295.

Marsh, H. W. (1990a). The causal ordering of academic self-concept and academic achievement: A multiwave, longitudinal panel analysis. Journal of Educational Psychology, 82, 646-656.

Marsh, H. W. (1990b). The structure of academic self-concept: The Marsh/Shavelson model. Journal of Educational Psychology, 82, 623-636.

Marsh, H. W., \& Hau, K. T. (2004). Explaining paradoxical relations between academic self-concepts and achievements: Cross-cultural generalizability of the internal/external frame of reference predictions across 26 countries. Journal of Educational Psychology, 96(1), 56-67.

Marsh, H. W., \& Martin, A. J. (2011). Academic self-concept and academic achievement: Relations and causal ordering. British Journal of Educational Psychology, 81, 59-77. https://doi.org/10.1348/ $000709910 x 503501$.

Marsh, H. W., \& Shavelson, R. J. (1985). Self-concept: Its multifaceted, hierarchical structure. Educational Psychologist, 20, 107-123. https://doi.org/10.1207/s15326985ep2003 1.

Marsh, H. W., Cairns, L., Relich, J., Barnes, J., \& Debus, R. L. (1984). The relationship between dimensions of self-attribution and dimensions of self-concept. Journal of Educational Psychology, 76(1), 332.

Marsh, H. W., Kong, C. K., \& Hau, K. T. (2000). Longitudinal multilevel models of the big-fish-little-pond effect on academic self-concept: Counterbalancing contrast and reflected-glory effects in Hong Kong schools. Journal of Personality and Social Psychology, 78, 337349. https://doi.org/10.1037/0022-3514.78.2.337.

Marsh, H. W., Lüdtke, O., Nagengast, B., Trautwein, U., Abduljabbar, A. S., Abdelfattah, F., \& Jansen, M. (2015). Dimensional comparison theory: Paradoxical relations between self-beliefs and achievements in multiple domains. Learning and Instruction, 35, 16-32.

Marsh, H. W., Pekrun, R., Murayama, K., Arens, A. K., Parker, P. D., Guo, J., et al. (2018). An integrated model of academic self-concept development: Academic self-concept, grades, test scores, and tracking over 6 years. Developmental Psychology, 54(2), 263-280.

McKenzie, D., \& Rapoport, H. (2011). Can migration reduce educational attainment? Evidence from Mexico. Journal of Population Economics, 24(4), 1331-1358.

Mendaglio, S. (2013). Gifted students transition to university. Gifted Education International, 29(3), 3-12.

Miserandino, M. (1997). Children who do well in school: Individual differences in perceived competence and autonomy in aboveaverage children. Journal of Educational Psychology, 88(2), 203214.

Möller, J., \& Marsh, H. W. (2013). Dimensional comparison theory. Psychological Review, 120, 544-560. https://doi.org/10.1037/ a0032459.

Möller, J., Pohlmann, B., Köller, O., \& Marsh, H. W. (2009). A metaanalytic path analysis of the internal/external frame of reference model of academic achievement and academic self-concept. Review of Educational Research, 79(3), 1129-1167.

Möller, J., Zimmermann, F., \& Köller, O. (2014). The reciprocal internal/ external frame of reference model using grades and test scores. British Journal of Education Psychology, 84(4), 591-611.

Muthén, L. K., \& Muthén, B. O. (1998-2012). Mplus user's guide (7th ed.). Los Angeles, CA: Muthén \& Muthén.

Nguyen, C. V. (2016). Does parental migration really benefit left-behind children? Comparative evidence from Ethiopia, India, Peru and Vietnam. Social Science \& Medicine, 153, 230-239.

Organization for Economic Cooperation and Development. (2014). PISA 2012 results: What students know and can do: Student performance in mathematics, reading and science (Volume I, Revised edition, February 2014), PISA, OECD Publishing, 19.

Parker, P. D., Marsh, H. W., Ciarrochi, J., Marshall, S., \& Abduljabbar, A. S. (2014). Juxtaposing math self-efficacy and self-concept as predictors of long-term achievement outcomes. Educational Psychology, 34(1), 29-48. https://doi.org/10.1080/01443410.2013. 797339.

Parker, P. D., Marsh, H. W., Lüdtke, O., \& Trautwein, U. (2013). Differential school contextual effects for math and English: Integrating the big-fish-little-pond effect and the internal/external frame of reference. Learning and Instruction, 23(1), 78-89.

Pinxten, M., Marsh, H. W., De Fraine, B., Van Den Noortgate, W., \& Van Damme, J. (2014). Enjoying mathematics or feeling competent in mathematics? Reciprocal effects on mathematics achievement and perceived math effort expenditure. British Journal of Educational Psychology, 84, 152-174.

Pinxten, M., Wouters, S., Preckel, F., Niepel, C., De Fraine, B., \& Verschueren, K. (2015). The formation of academic self-concept in elementary education: A unifying model for external and internal comparisons. Contemporary Educational Psychology, 41, 124-132. https://doi.org/10.1016/j.cedpsych.2014.12.003.

Preacher, K. J., Zhang, Z., \& Zyphur, M. J. (2011). Alternative methods for assessing mediation in multilevel data: The advantage of multilevel SEM. Structural Equation Modeling, 18, 161-182.

Preacher, K. J., Zyphur, M. J., \& Zhang, Z. (2010). A general multilevel SEM framework for assessing multilevel mediation. Psychological Methods, 15, 209-233.

Raudenbush, S. W., \& Bryk, A. S. (2002). Hierarchical linear models: Applications and data analysis methods. Newbury Park, CA: Sage.

Raudenbush, S., Bryk, A., \& Congdon, R. (2008). Hierarchical linear and nonlinear modeling (version 6.06). Lincolnwood, IL: Scientific Software International, Inc. 
Retelsdorf, J., Köller, O., \& Möller, J. (2014). Reading achievement and reading self-concept-Testing the reciprocal effects model. Learning and Instruction, 29, 21-30.

Rinn, A. N., Miner, K. N., \& Taylor, A. B. (2013). Family context predictors of math self-concept among undergraduate stem majors: An analysis of gender differences. Journal of the Scholarship of Teaching and Learning, 13(2), 116-132.

Roy, A. K., Singh, P., \& Roy, U. N. (2015). Impact of rural-urban labour migration on education of children: A case study of left behind and accompanied migrant children in India. Space and Culture, India, 2(4), 17-34.

Shavelson, R. J., Hubner, J. J., \& Stanton, G. C. (1976). Self-concept: Validation of construct interpretations. Review of Educational Research, 46(3), 407-441.

Skaalvik, E. M., \& Hagtvet, K. A. (1990). Academic achievement and self-concept: An analysis of causal predominance in a developmental perspective. Journal of Personality and Social Psychology, 58, 292-307.

Skaalvik, E. M., \& Skaalvik, S. (2009). Self-concept and self-efficacy in mathematics: Relation with mathematics motivation and achievement. Journal of Education Research, 3(3), 255-278.

Skaalvik, E. M., \& Valas, H. (1999). Relations among achievement, selfconcept, and motivation in mathematics and language arts: A longitudinal study. The Journal of Experimental Education, 67(2), 135149.

Stäbler, F., Dumont, H., Becker, M., \& Baumert, J. (2017). What happens to the fish's achievement in a little pond? A simultaneous analysis of class-average achievement effects on achievement and academic self-concept. Journal of Educational Psychology, 2, 191-207. https://doi.org/10.1037/edu0000135.

State Council of the People's Republic of China. (2016). The Opinion of the State Council Concerning the Strengthening of Jobs for Caring and Protecting Rural Left-Behind Children. http://www.gov.cn/ zhengce/content/2016-02/14/content 5041066.htm.

Sun, X., Tian, Y., Zhang, Y., Xie, X., Heath, M. A., \& Zhou, Z. (2015). Psychological development and educational problems of left-behind children in rural China. School Psychology International, 36, 227 252.

Susperreguy, M. I., Davis-Kean, P. E., Duckworth, K., \& Chen, M. (2017). Self-concept predicts academic achievement across levels of the achievement distribution: Domain specificity for math and reading. Child Development, 89(6), 2196-2214.

Schurtz, I. M., Pfost, M., \& Artelt, C. (2014). Do self-concept differences vary in dependence of the achievement level? Differential relations in German, English, and mathematics. Zeitschrift für Pädagogische Psychologie, 28, 31-42. https://doi.org/10.1024/1010-0652/ a000122.

Tarroja, M. C. H., \& Fernando, K. C. (2013). Providing psychological services for children of overseas Filipino workers (OFWs): A challenge for school psychologists in the Philippines. School Psychology International, 34, 202-212.

Trautwein, U., \& Moller, J. (2016). Self-concept: Determinants and consequences of academic self-concept in school contexts. In A. Lipnevich, F. Preckel, \& R. D. Roberts (Eds.), Psychosocial skills and school systems in the twenty-first century: Theory, research, and applications (pp. 187-214). Berlin, Germany: Springer.

Triandis, H. C. (1989). The self and social behavior in differing cultural contexts. Psychological Review, 96(3), 506-520.

Valentine, J. C., DuBois, D. L., \& Cooper, H. (2004). The relation between self-beliefs and academic achievement: A meta-analytic review. Educational Psychologist, 39, 111-133.
Valtolina, G. G., \& Colombo, C. (2012). Psychological well-being, family relations, and developmental issues of children left behind. Psychological Reports, 111(3), 905-928. https://doi.org/10.2466/ 21.10.17.PR0.111.6.905-928

Vanore, M., Mazzucato, V., \& Siegel, M. (2015). 'Left behind' but not left alone: Parental migration and the psychosocial health of children in Moldova. Social Science \& Medicine, 132, 252-260.

Voelkl, K. E. (1997). Identification with school. American Journal of Education, 105, 204-319.

Walton, G. M., \& Cohen, G. L. (2007). A question of belonging: Race, social fit, and achievement. Journal of Personality and Social Psychology, 92, 82-96. https://doi.org/10.1037/0022-3514.92.1.82.

Wang, L., \& Mesman, J. (2015). Child development in the face of ruralto-urban migration in China: A meta-analytic review. Perspectives on Psychological Science, 10(6), 813-831. https://doi.org/10.1177/ 1745691615600145.

Wang, X., Ling, L., Su, H., Cheng, J., Jin, L., \& Sun, Y. H. (2014). Selfconcept of left-behind children in China: A systematic review of the literature. Child: Care, Health and Development, 41(3), 346-355.

Wang, Z. (2015). Examining big-fish-little-pond-effects across 49 countries: A multilevel latent variable modelling approach. Educational Psychology, 35, 228-251.

Wen, M., \& Lin, D. (2012). Child development in rural China: Children left behind by their migrant parents and children of nonmigrant families. Child Development, 83(1), 120-136.

Wolters, C. A. (2003). Regulation of motivation: Evaluating an underemphasized aspect of self-regulated learning. Educational Psychologist, 38, 189-205.

Wouters, S., Colpin, H., Van Damme, J., De Laet, S., \& Verschueren, K. (2013). Early adolescents' academic self-concept formation: Do classmates or friends matter most? Learning and Individual Differences, 27, 193-200. https://doi.org/10.1016/j.lindif.2013.09. 002.

Yang, P. (2008). The model of relation between students' academic selfconcept and school performance and the research of imagery training. Shanghai Normal University: Unpublished master thesis.

Yao, J. H., \& Mao, Y. Q. (2008). Research on the school work mental characteristics of western rural parent-absent children and its countermeasure of school management. Educational Research, 2, 33-38.

Zhang, C. (2013). Positive youth development: Compositions, measurement and the roles. Unpublished doctoral dissertation. Changchun: Northeast Normal University.

Zhang, H., Behrman, J., Fan, S., Wei, X., \& Zhang, J. (2014). Does parental absence reduce cognitive achievements? Evidence from rural China. Journal of Development Economics, 111, 181-195.

Zhang, N., Bécares, L., \& Chandola, T. (2015). Does the timing of parental migration matter for child growth? A life course study on leftbehind children in rural China. BMC Public Health, 15(1), 966-978. https://doi.org/10.1186/s12889-015-2296-y.

Zhao, F., \& Yu, G. (2016). Parental migration and rural left-behind children's mental health in China: A meta-analysis based on mental health test. Journal of Child and Family Studies, 25(12), 34623472. https://doi.org/10.1007/s10826-016-0517-3.

Zhao, X., Chen, J., Chen, M. C., Lv, X. L., Jiang, Y. H., \& Sun, Y. H. (2014). Left-behind children in rural China experience higher levels of anxiety and poorer living conditions. Acta Paediatrica, 103(6), 665-670. https://doi.org/10.1111/apa.12602.

Publisher's Note Springer Nature remains neutral with regard to jurisdictional claims in published maps and institutional affiliations. 